Article

\title{
A Comparison of Land Surface Water Mapping Using the Normalized Difference Water Index from TM, ETM+ and ALI
}

\section{Wenbo Li ${ }^{1}$, Zhiqiang Du ${ }^{2, *}$, Feng Ling ${ }^{3}$, Dongbo Zhou ${ }^{4}$, Hailei Wang ${ }^{1}$, Yuanmiao Gui ${ }^{1}$, Bingyu Sun ${ }^{1}$ and Xiaoming Zhang ${ }^{1}$}

1 Institute of Intelligent Machines, Chinese Academy of Sciences, Hefei 230031, China;

E-Mails: wbli@iim.ac.cn (W.L.); hailei@mail.ustc.edu.cn (H.W.); smalltalkman@foxmail.com (Y.G.); bysun@iim.ac.cn (B.S.); xmzhang@iim.ac.cn (X.Z.)

2 State Key Laboratory of Information Engineering in Surveying, Mapping and Remote Sensing, Wuhan University, Wuhan 430079, China

3 Institute of Geodesy and Geophysics, Chinese Academy of Sciences, Wuhan 430077, China; E-Mail: lingf@whigg.ac.cn

4 National Engineering Research Center for E-Learning, Central China Normal University, Wuhan 430079, China; E-Mail: dongbozhou@gmail.com

* Author to whom correspondence should be addressed; E-Mail: duzhiqiang@whu.edu.cn; Tel.: +86-27-6877-8779; Fax: +86-27-6877-8229.

Received: 5 August 2013; in revised form: 15 October 2013 / Accepted: 16 October 2013 / Published: 28 October 2013

\begin{abstract}
Remote sensing has more advantages than the traditional methods of land surface water (LSW) mapping because it is a low-cost, reliable information source that is capable of making high-frequency and repeatable observations. The normalized difference water indexes (NDWIs), calculated from various band combinations (green, near-infrared (NIR), or shortwave-infrared (SWIR)), have been successfully applied to LSW mapping. In fact, new NDWIs will become available when Advanced Land Imager (ALI) data are used as the ALI sensor provides one green band (Band 4), two NIR bands (Bands 6 and 7), and three SWIR bands (Bands 8, 9, and 10). Thus, selecting the optimal band or combination of bands is critical when ALI data are employed to map LSW using NDWI. The purpose of this paper is to find the best performing NDWI model of the ALI data in LSW map. In this study, eleven NDWI models based on ALI, Thematic Mapper (TM), and Enhanced Thematic Mapper Plus (ETM+) data were compared to assess the performance of ALI data in LSW mapping, at three different study sites in the Yangtze River Basin, China. The contrast method, Otsu method, and confusion matrix were calculated to
\end{abstract}


evaluate the accuracies of the LSW maps. The accuracies of LSW maps derived from eleven NDWI models showed that five NDWI models of the ALI sensor have more than an overall accuracy of $91 \%$ with a Kappa coefficient of 0.78 of LSW maps at three test sites. In addition, the NDWI model, calculated from the green (Band 4: 0.525-0.605 $\mu \mathrm{m}$ ) and SWIR (Band 9: $1.550-1.750 \mu \mathrm{m}$ ) bands of the ALI sensor, namely $\mathrm{NDWI}_{\mathrm{A} 4,9}$, was shown to have the highest LSW mapping accuracy, more than the other NDWI models. Therefore, the $\mathrm{NDWI}_{\mathrm{A} 4,9}$ is the best indicator for LSW mapping of the ALI sensor. It can be used for mapping LSW with high accuracy.

Keywords: remote sensing; image segmentation; land surface water mapping; Advanced Land Imager (ALI); normalized difference water index; Landsat

\section{Introduction}

Water resources are one of the irreplaceable strategic resources for human survival. Land surface water (LSW) is an important part of the water cycle. LSW mapping, using remote sensing techniques, plays an important role in wetland monitoring [1-3], flood monitoring [4-6], flood disaster assessment [7-10], surface water area estimation [11-14], and water resources management [15-17]. Over three decades, multi-resource remote sensing data, such as data from the Advanced Very High Resolution Radiometer (AVHRR) [5,6,18], Moderate-resolution Imaging Spectroradiometer (MODIS) [16,19], Small Satellite Constellation For Environment and Disaster Monitoring And Forecasting A/B Satellites (HJ-1A/B) [12,20], Multispectral Scanner System (MSS) [6,11], Thematic Mapper (TM) [13,20,21], and Enhanced Thematic Mapper Plus (ETM+) [7,11] have been employed to extract information on land surface water bodies. One widely used remote sensing dataset for LSW mapping are the TM and ETM+ images provided by the Landsat series satellites [11]. The Landsat-7 mission was flawless until May, 2003, when a hardware component failure left wedge-shaped spaces of missing data on either side of ETM+ images. The U.S. Geological Survey (USGS) stopped acquiring images from the 27-year-old Landsat-5 satellite in November 2011, due to a rapidly degrading electronic component that threatened to end the Landsat-5 mission. Fortunately, the National Aeronautics and Space Administration (NASA) launched the eighth Landsat satellite (Landsat-8) on 11 February 2013. NASA also launched a technology validation and demonstration mission satellite called Earth Observation-1 (EO-1). The Advanced Land Imager (ALI) instrument onboard EO-1 was used to validate and demonstrate technology for Landsat-8. The primary focus of EO-1 is to develop and test a set of advanced technology land-imaging instruments. EO-1 has been inserted into the same orbit as the Landsat-7 satellite, and is taking a series of the same images. Operating in a pushing broom pattern, at an altitude of $705 \mathrm{~km}$, the ALI sensor provides panchromatic images at $10 \mathrm{~m}$ spatial resolution and nine bands of multispectral images at $30 \mathrm{~m}$ resolution. These nine multispectral bands have been designed to simulate the six Landsat-7 bands, with the three additional bands covering $0.433-0.453 \mu \mathrm{m}, 0.845-0.890 \mu \mathrm{m}$, and $1.20-1.30 \mu \mathrm{m}$. ALI remote sensing images are potentially useful in various applications related to land cover mapping [22], vegetation mapping [23,24], forest classification [25], and the evaluation of dissolved organic matter in lake 
water [26]. Many studies have also examined the potential comparison of the ALI sensor to the TM and ETM+ sensors [24,27-29]. However, inadequate attention has been paid to examining ALI's capability of delineating water bodies and mapping LSW, particularly in comparison to other sensors. The purpose of this study is to assess the potential of the ALI data for LSW mapping so that EO-1 and the series of Landsat satellite data can be clearly used to delineate water body information and to map LSW in the future.

Surface water body information detection is of great significance to very related research in remote sensing [11]. Various surface water body information extracting algorithms [1-3,11-13,18-21,30-38] have been developed as they are the key points for transferring remotely sensed images into information for practical applications, such as LSW mapping [36]. In brief, these algorithms identify water in two broad ways: the general feature classification method $[2,3,30,31,35,39]$ and the thematic water body information detection method [1,11-13,18-21,32-34,36]. The general classification methods can be realized by maximum likelihood supervised classification [35], decision tree classification $[3,16]$, support vector machine classification [31], artificial neural network classification [30,37], etc. The thematic water body information extraction methods can be generally divided into two categories according to the number of bands used: the single-band method and the multi-band method. The single-band method usually involves choosing a characteristic band of water from a multispectral image, then determining a threshold at which to discriminate water from other surfaces [33]. The multi-band methods, which are based on the spectral water index [32,34,38], are better at the detection of LSW body information than the single-band method is because they take advantage of reflectivity differences of each involved band and extract water-body information based on the analysis of signature differences between water and other surfaces [36].

General feature classification methods are common methods for extracting water bodies and mapping LSW. However, general classification method is based on the assumption that the pixel is pure. When multiple features are present within a single pixel, the accuracy of such classification methods will depend on the complexity of the landscape and the thoroughness of an extended training process [39]. In addition, most of these approaches are highly reliant on human expertise and knowledge of the local area. They will meet difficulties when the aim is to perform a rapid and reproducible extraction of water-body information because water bodies, such as floods, tides, and storm surges, can be fast-moving [40]. Spectral water index methods, such as the normalized difference water index, namely, McFeeters's NDWI [32], which is calculated from one green-band image and one NIR-band image, and modification of the normalized difference water index, namely, Xu's NDWI or MNDWI [34], which is calculated from one green-band image and one SWIR-band image, can extract water body information more accurately, quickly, and easily than general feature classification methods. Moreover, McFeeters's NDWI and Xu's NDWI have been successfully used to extract water information from remotely sensed data $[18,20,21,41,42]$. Therefore, we used McFeeters's NDWI and Xu's NDWI as the primary tools for this work on LSW mapping from ALI remotely sensed images. McFeeters's NDWI forms two models and Xu's NDWI forms three models as the ALI sensor can supply one green band (Band 4), two NIR bands (Bands 6 and 7), and three SWIR bands (Bands 8, 9, and 10) data. We found that these five water body information detection models produce different LSW mapping results. Hence, we need to know which NDWI model among these spectral water indices performs best for LSW mapping of the ALI sensor. In other words, we need to 
understand which band (green, NIR, and SWIR) or band combination is the best indicator of LSW mapping from ALI remote sensing images. Thus, we employed McFeeters's and Xu's NDWIs to determine which model is the best indicator for LSW mapping when ALI data are used. We analyzed the performance of LSW mapping based on TM, ETM+, and ALI data using different NDWI models in three regions within the Yangtze River Basin, China.

\section{Study Area and Materials}

\subsection{Study Area}

The portion of the Yangtze River Basin inside Hubei province, China, was selected as the study area (Figure 1). It is located between $30^{\circ} 13^{\prime}-30^{\circ} 50^{\prime} \mathrm{N}$ and $110^{\circ} 56^{\prime}-111^{\circ} 52^{\prime} \mathrm{E}$. The terrain of the study area includes mountains, foothills, and plains, from the northwest to the southeast. The highest elevation, 2,399 m, occurs in the western mountainous area, and the lowest elevation, approximately $36 \mathrm{~m}$, is found in the southeast plain area. The study area has many types of water features, including rivers (e.g., the Yangtze River and the Qingjiang River), lakes, reservoirs (e.g., the Three Gorges Reservoir formed by the Three Gorges Dam and the Gaobazhou Reservoir formed by the Gaobazhou Dam), ponds, and ditches. The land cover types of the study area include vegetation (trees, bushes, fields, and lawns), soil, rock, building (hydraulic structures, roads), and water bodies (rivers, lakes, reservoirs, ponds, wetlands, and ditches) [11]. The terrains and land cover types of the study area can be used to verify the validity of LSW mapping from EO-1 ALI remotely sensed images.

Figure 1. Location of the study area.

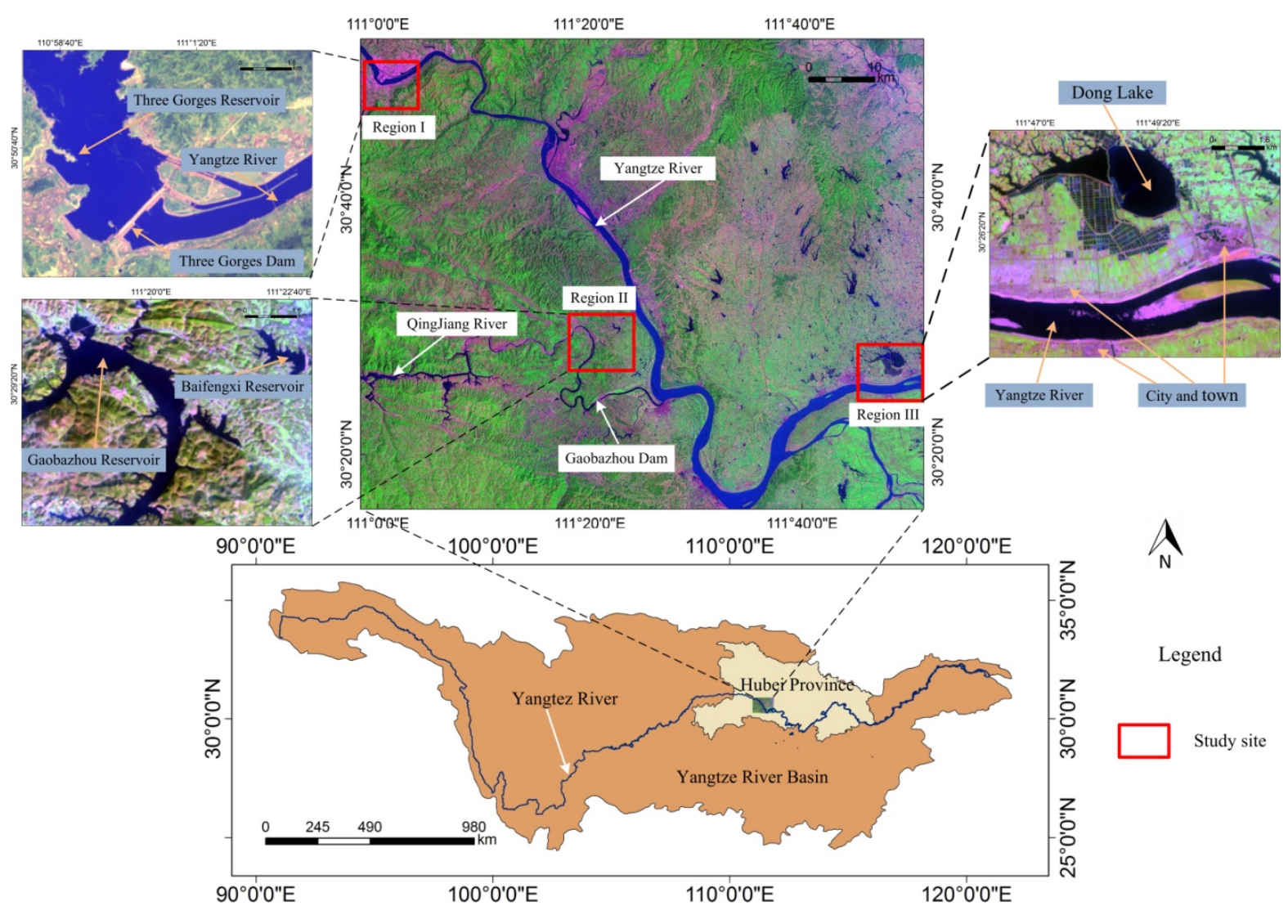


To find which NDWI model of the ALI data is the best indicator for LSW mapping, three study sites (Figure 1), each sized $300 \times 240$ pixels and having different water features (e.g., rivers, reservoirs, and lakes) and background features (non-water land cover types) were selected as sample areas for detailed analysis. The Three Gorges Reservoir and the Yangtze River were selected as the main water features of Region I. The main background features of Region I are the Three Gorges Dam and the vegetation features. In Region II, the main water bodies are the Baifengxi Reservoir and the Gaobazhou Reservoir, and the background features are vegetation features. In Region III, the main water bodies are the Yangtze River and Dong Lake, and the background features include vegetation, sandbank, and buildings [12].

Table 1. Specifications of the Thematic Mapper (TM), Enhanced Thematic Mapper Plus $(\mathrm{ETM}+)$, and Advanced Land Imager (ALI) data used in this study.

\begin{tabular}{|c|c|c|c|c|c|c|c|}
\hline Satellite & Sensor & $\begin{array}{l}\text { Path/ } \\
\text { Row }\end{array}$ & $\begin{array}{l}\text { Acquisition } \\
\text { Date }\end{array}$ & $\begin{array}{l}\text { Resolution } \\
\text { (m) }\end{array}$ & $\begin{array}{l}\text { File } \\
\text { Format }\end{array}$ & Producer & Wavelength $(\mu \mathrm{m})$ \\
\hline \multirow{7}{*}{ Landsat-5 } & \multirow{7}{*}{$\mathrm{TM}$} & \multirow{7}{*}{$125 / 39$} & \multirow{7}{*}{$\begin{array}{l}2005-09-09 \\
2010-05-02\end{array}$} & \multirow{5}{*}{30} & \multirow{5}{*}{ GeoTiff } & \multirow{5}{*}{ USGS } & Band1(Blue): $0.450-0.520$ \\
\hline & & & & & & & Band2 (Green): $0.520-0.600$ \\
\hline & & & & & & & Band3 (Red): 0.630-0.690 \\
\hline & & & & & & & Band4 (NIR): 0.760-0.900 \\
\hline & & & & & & & Band5 (SWIR): $1.550-1.750$ \\
\hline & & & & 120 & GeoTiff & USGS & Band6 (TIR): $10.400-12.500$ \\
\hline & & & & 30 & GeoTiff & USGS & Band7 (SWIR): $2.080-2.350$ \\
\hline \multirow{8}{*}{ Landsat-7 } & \multirow{8}{*}{ ETM+ } & \multirow{8}{*}{$124 / 39$} & \multirow{8}{*}{ 2003-03-29 } & & & & Band1(Blue): $0.450-0.515$ \\
\hline & & & & & & & Band2 (Green): 0.525-0.605 \\
\hline & & & & 30 & GeoTiff & USGS & Band3 (Red): 0.630-0.690 \\
\hline & & & & & & & Band4 (NIR): $0.750-0.900$ \\
\hline & & & & & & & Band5 (SWIR): $1.550-1.750$ \\
\hline & & & & 60 & GeoTiff & USGS & Band6 (TIR): 10.400-12.500 \\
\hline & & & & 30 & GeoTiff & USGS & Band7 (SWIR): 2.090-2.350 \\
\hline & & & & 15 & GeoTiff & USGS & Band8 (PAN): $0.520-0.900$ \\
\hline \multirow{10}{*}{ EO-1 } & \multirow{10}{*}{ ALI } & \multirow{10}{*}{$\begin{array}{l}124 / 39 \\
125 / 39 \\
125 / 38\end{array}$} & \multirow{10}{*}{$\begin{array}{l}2003-03-29 \\
2005-10-21 \\
2010-09-03\end{array}$} & 10 & GeoTiff & USGS & Band1(PAN): $0.480-0.690$ \\
\hline & & & & \multirow{9}{*}{30} & \multirow{9}{*}{ GeoTiff } & \multirow{9}{*}{ USGS } & Band2(Blue): $0.433-0.453$ \\
\hline & & & & & & & Band3 (Blue): $0.450-0.515$ \\
\hline & & & & & & & Band4 (Green): 0.525-0.605 \\
\hline & & & & & & & Band5 (Red): 0.630-0.690 \\
\hline & & & & & & & Band6 (NIR): 0.775-0.805 \\
\hline & & & & & & & Band7 (NIR):0.845-0.890 \\
\hline & & & & & & & Band8 (SWIR): $1.200-1.300$ \\
\hline & & & & & & & Band9 (SWIR): $1.550-1.750$ \\
\hline & & & & & & & Band10 (SWIR): $2.080-2.350$ \\
\hline
\end{tabular}

\subsection{Materials}

Six satellite images from EO-1 and Landsat archived on USGS server (http://earthexplorer.usgs.gov/) were used in this study (Table 1). Three ALI images were separately acquired on 29 March 2003 (path/row 124/39), 21 October 2005 (path/row 125/39), and 3 September 2010 (path/row 125/38). The 
selected ETM+ images were acquired on 29 March 2003 (path/row 124/39). Two TM datasets were separately acquired on 9 September 2005, and 2 May 2010 (path/row 125/39). The ALI, TM and ETM+ data have six bands with similar spectral ranges (e.g., blue: $0.450-0.520 \mu \mathrm{m}$, green: $0.520-0.600 \mu \mathrm{m}$, red: $0.630-0.690 \mu \mathrm{m}$, NIR: $0.750-0.900 \mu \mathrm{m}$, and SWIR: $1.550-1.750 \mu \mathrm{m}$ and $2.080-2.350 \mu \mathrm{m}$ ). All images employed in the present study are level-1 products of USGS, referenced in the World Geodetic System (WGS84) datum, in GeoTiff format, and are projected using the Universal Transverse Mercator system (zone UTM 49 North). Further information about the specifications of the remote sensing data used in this study is given in Table 1.

\section{Methodology}

\subsection{Data Pre-Processing}

The parameters used in McFeeters's NDWI and Xu's NDWI require physical units, such as at-sensor radiance or top-of-atmosphere (TOA) reflectance, rather than the raw quantized calibrated pixel value (DN). There are three advantages to using TOA reflectance instead of at-sensor spectral radiance when comparing images from different sensors $[42,43]$. First, TOA reflectance removes the cosine effect at different solar zenith angles due to the time difference between data acquisitions. Second, TOA reflectance compensates for different values of the exo-atmospheric solar irradiance arising from spectral band differences. Third, TOA reflectance corrects for the variation in the earth-sun distance between different data acquisition dates. Therefore, we used the TOA reflectance of the ALI, TM, and ETM+ data to be used in this study. TOA reflectance can be obtained from the quantized calibrated pixel value, as given by [43]:

$$
\rho_{\lambda}=\frac{\pi \cdot L_{\lambda} \cdot \mathrm{d}^{2}}{E S U N_{\lambda} \cdot \cos \theta_{\mathrm{s}}}
$$

where $\rho_{\lambda}$ is the TOA reflectance of wavelength $\lambda$ [unitless], $d$ is the earth-sun distance [astronomical units], $E S U N_{\lambda}$ is mean exo-atmospheric solar irradiance $\left[\mathrm{W} /\left(\mathrm{m}^{2} \cdot \mu \mathrm{m}\right)\right], \theta_{S}$ is the solar zenith angle [degrees], and $L_{\lambda}$ is the spectral radiance at wavelength $\lambda$ at the sensor's aperture $\left[\mathrm{W} /\left(\mathrm{m}^{2} \cdot \mathrm{sr} \cdot \mu \mathrm{m}\right)\right] . L_{\lambda}$ can be obtained from the quantized calibrated pixel value also as given by [43]:

$$
L_{\lambda}=\left(\frac{L M A X_{\lambda}-L M I N_{\lambda}}{Q_{c a l \text { max }}-Q_{c a l \text { min }}}\right)\left(Q_{c a l}-Q_{c a l \text { min }}\right)+L M I N_{\lambda}
$$

where $L M A X_{\lambda}$ is the spectral at-sensor radiance that is scaled to $Q_{\text {calmax }}\left[\mathrm{W} /\left(\mathrm{m}^{2} \mathrm{sr} \mu \mathrm{m}\right)\right], L_{M I N}$ is spectral at-sensor radiance that is scaled to $Q_{\text {calmin }}\left[\mathrm{W} /\left(\mathrm{m}^{2} \cdot \mathrm{sr} \cdot \mu \mathrm{m}\right)\right], Q_{\text {calmax }}$ is the maximum quantized calibrated pixel value corresponding to $L M A X_{\lambda}[\mathrm{DN}], Q_{\text {calmin }}$ is the minimum quantized calibrated pixel value corresponding to $L M I N_{\lambda}$ [DN], and $Q_{c a l}$ is the quantized calibrated pixel value [DN].

The parameters in Equations (1) and (2) can be read from the header files of the ALI, TM, and $\mathrm{ETM}+$ datasets or be retrieved from the USGS website (http://earthexplorer.usgs.gov/).

\subsection{Spectral Water Index Methods}

We employed two spectral water index methods, McFeeters's NDWI and Xu's NDWI, to find which NDWI model of the ALI data is the best indicator of LSW mapping. The foundation of the spectral water index method is that a water body has a strong absorbability and low radiation from 
visible wavelengths to infrared wavelengths. The division of operations of the spectral water index method not only enhances the spectral signals by contrasting the reflectance between different wavelengths but also cancels out a large portion of the noise components that are common in different wavelength regions [38].

McFeeters's NDWI [32] is defined as

$$
N D W I=\frac{\rho_{\text {Green }}-\rho_{\text {NIR }}}{\rho_{\text {Green }}+\rho_{\text {NIR }}}
$$

where $\rho_{\text {Green }}$ and $\rho_{\text {NIR }}$ are the reflectance of the green and NIR bands, respectively.

McFeeters's NDWI is designed to (1) maximize the reflectance of a water body by using green wavelengths, (2) minimize the low reflectance in NIR of water bodies, and (3) take advantage of the high reflectance in NIR of vegetation and soil features [42]. As a result, the water body information will be enhanced and the background (vegetation and soil features) information will be restricted in McFeeters's NDWI images. This means that the water bodies can be identified by applying a threshold to McFeeters's NDWI images.

McFeeters's NDWI can enhance information about water bodies and restrict information about vegetation and soil features, but it cannot completely distinguish built-up features from water bodies. $\mathrm{Xu}$ 's NDWI [34] was developed to address this problem; it is defined as

$$
M N D W I=\frac{\rho_{\text {Green }}-\rho_{\text {SWIR }}}{\rho_{\text {Green }}+\rho_{\text {SWIR }}}
$$

where $\rho_{\text {SWIR }}$ is the reflectance in the SWIR band.

Xu's NDWI can enhance open-water features while efficiently suppressing and even removing built-up features as well as vegetation and soil features.

Table 2. Normalized difference water index equations and associated sensors (T: TM,

\begin{tabular}{|c|c|c|}
\hline Sensor & NDWI Equation & Symbol and Notation \\
\hline $\mathrm{TM}$ & $\begin{array}{l}\mathrm{NDWI}_{\mathrm{T} 2,4}=\left(\mathrm{B}_{\mathrm{T} 2}-\mathrm{B}_{\mathrm{T} 4}\right) /\left(\mathrm{B}_{\mathrm{T} 2}+\mathrm{B}_{\mathrm{T} 4}\right) \\
\mathrm{NDWI}_{\mathrm{T} 2,5}=\left(\mathrm{B}_{\mathrm{T} 2}-\mathrm{B}_{\mathrm{T} 5}\right) /\left(\mathrm{B}_{\mathrm{T} 2}+\mathrm{B}_{\mathrm{T} 5}\right) \\
\mathrm{NDWI}_{\mathrm{T} 2,7}=\left(\mathrm{B}_{\mathrm{T} 2}-\mathrm{B}_{\mathrm{T} 7}\right) /\left(\mathrm{B}_{\mathrm{T} 2}+\mathrm{B}_{\mathrm{T} 7}\right)\end{array}$ & $\begin{array}{l}\mathrm{NDWI}_{\mathrm{T} 2,4} \text { is the McFeeters's NDWI for the TM sensor; } \mathrm{NDWI}_{\mathrm{T} 2,5} \\
\text { and } \mathrm{NDWI}_{\mathrm{T} 2,7} \text { are the Xu's NDWIs for the TM sensor; } \mathrm{B}_{\mathrm{T} 2}, \mathrm{~B}_{\mathrm{T} 4} \text {, } \\
\mathrm{B}_{\mathrm{T} 5} \text { and } \mathrm{B}_{\mathrm{T} 7} \text { are Bands } 2,4,5 \text {, and } 7 \text { of the TM sensor, respectively. }\end{array}$ \\
\hline ETM+ & $\begin{array}{l}\mathrm{NDWI}_{\mathrm{E} 2,4}=\left(\mathrm{B}_{\mathrm{E} 2}-\mathrm{B}_{\mathrm{E} 4}\right) /\left(\mathrm{B}_{\mathrm{E} 2}+\mathrm{B}_{\mathrm{E} 4}\right) \\
\mathrm{NDWI}_{\mathrm{E} 2,5}=\left(\mathrm{B}_{\mathrm{E} 2}-\mathrm{B}_{\mathrm{E} 5}\right) /\left(\mathrm{B}_{\mathrm{E} 2}+\mathrm{B}_{\mathrm{E} 5}\right) \\
\mathrm{NDWI}_{\mathrm{E} 2,7}=\left(\mathrm{B}_{\mathrm{E} 2}-\mathrm{B}_{\mathrm{E} 7}\right) /\left(\mathrm{B}_{\mathrm{E} 2}+\mathrm{B}_{\mathrm{E} 7}\right)\end{array}$ & $\begin{array}{l}\mathrm{NDWI}_{\mathrm{E} 2,4} \text { is the McFeeters's NDWI for the ETM+ sensor; } \\
\mathrm{NDWI}_{\mathrm{E} 2,5} \text { and } \mathrm{NDWI}_{\mathrm{E} 2,7} \text { are the Xu's NDWIs for the ETM+ } \\
\text { sensor; } \mathrm{B}_{\mathrm{E} 2}, \mathrm{~B}_{\mathrm{E} 4}, \mathrm{~B}_{\mathrm{E} 5} \text { and } \mathrm{B}_{\mathrm{E} 7} \text { are Bands } 2,4,5 \text {, and } 7 \text { of the } \\
\text { ETM+ sensor, respectively. }\end{array}$ \\
\hline ALI & $\begin{array}{l}\mathrm{NDWI}_{\mathrm{A} 4,6}=\left(\mathrm{B}_{\mathrm{A} 4}-\mathrm{B}_{\mathrm{A} 6}\right) /\left(\mathrm{B}_{\mathrm{A} 4}+\mathrm{B}_{\mathrm{A} 6}\right) \\
\mathrm{NDWI}_{\mathrm{A} 4,7}=\left(\mathrm{B}_{\mathrm{A} 4}-\mathrm{B}_{\mathrm{A} 7}\right) /\left(\mathrm{B}_{\mathrm{A} 4}+\mathrm{B}_{\mathrm{A} 7}\right) \\
\mathrm{NDWI}_{\mathrm{A} 4,8}=\left(\mathrm{B}_{\mathrm{A} 4}-\mathrm{B}_{\mathrm{A} 8}\right) /\left(\mathrm{B}_{\mathrm{A} 4}+\mathrm{B}_{\mathrm{A} 8}\right) \\
\mathrm{NDWI}_{\mathrm{A} 4,9}=\left(\mathrm{B}_{\mathrm{A} 4}-\mathrm{B}_{\mathrm{A} 9}\right) /\left(\mathrm{B}_{\mathrm{A} 4}+\mathrm{B}_{\mathrm{A} 9}\right) \\
\mathrm{NDWI}_{\mathrm{A} 4,10}=\left(\mathrm{B}_{\mathrm{A} 4}-\mathrm{B}_{\mathrm{A} 10}\right) /\left(\mathrm{B}_{\mathrm{A} 4}+\mathrm{B}_{\mathrm{A} 10}\right)\end{array}$ & $\begin{array}{l}\mathrm{NDWI}_{\mathrm{A} 4,6} \text { and } \mathrm{NDWI}_{\mathrm{A} 4,7} \text { are the McFeeters's NDWIs for the ALI } \\
\text { sensor; } \mathrm{NDWI}_{\mathrm{A} 4,8}, \mathrm{NDWI}_{\mathrm{A} 4,9} \text { and } \mathrm{NDWI}_{\mathrm{A} 4,10} \text { are the Xu's NDWIs } \\
\text { for the ALI sensor; } \mathrm{B}_{\mathrm{A} 4}, \mathrm{~B}_{\mathrm{A} 6}, \mathrm{~B}_{\mathrm{A} 7}, \mathrm{~B}_{\mathrm{A} 8}, \mathrm{~B}_{\mathrm{A} 9} \text {, and } \mathrm{B}_{\mathrm{A} 10} \text { are Bands } 4 \text {, } \\
6,7,8,9 \text {, and } 10 \text { of the } \mathrm{ALI} \text { sensor, respectively. }\end{array}$ \\
\hline
\end{tabular}
$\mathrm{E}: \mathrm{ETM}+, \mathrm{A}: \mathrm{ALI})$.

In this study, Bands 4, 6, and 7 of the ALI sensor were selected to form two NDWI models, namely, $\mathrm{NDWI}_{\mathrm{A} 4,6}$ and $\mathrm{NDWI}_{\mathrm{A} 4,7}$, based on McFeeters's NDWI (Equation (3)). Bands 2 and 4 of the TM and $\mathrm{ETM}+$ sensors were used to form two NDWI models, namely, $\mathrm{NDWI}_{\mathrm{T} 2,4}$ and $\mathrm{NDWI}_{\mathrm{E} 2,4}$, using McFeeters's NDWI. For Xu's NDWI (Equation (4)), Bands 4, 8, 9, and 10 of the ALI sensor were 
employed to form three NDWI models, namely, $\mathrm{NDWI}_{\mathrm{A} 4,8}, \mathrm{NDWI}_{\mathrm{A} 4,9}$, and $\mathrm{NDWI}_{\mathrm{A} 4,10}$. Similarly, Bands 2, 5, and 7 of the TM and ETM+ sensors were used to form four NDWI models, namely, $\mathrm{NDWI}_{\mathrm{T} 2,5}, \mathrm{NDWI}_{\mathrm{T} 2,7}, \mathrm{NDWI}_{\mathrm{E} 2,5}$, and $\mathrm{NDWI}_{\mathrm{E} 2,7}$ (Table 2).

\subsection{Image Threshold Segmentation}

Threshold selection is a key step in defining McFeeters's or Xu's NDWIs. The threshold values for McFeeters's and Xu's NDWIs were set to zero [32,34], but threshold adjustment in individual situations can achieve a more accurate delineation of water bodies [38]. Hence, dynamic or variational thresholds are needed when different regions or different phases of remote sensing data are employed to detect water body information [11]. The maximum between-class variance method (the Otsu method) is one such dynamic threshold method [44]. In this study, the Otsu method was used to determine the threshold for separating water bodies from the background features.

Now, assume that the NDWI pixels range from $[a, \cdots, b]$, where $-1 \leq a<b \leq 1$. Using the Otsu method, the pixels can be divided into two classes: a non-water class ranging from $[a, \cdots, t]$ and a water class ranging from $[t, \cdots, b]$, where $t$ is the threshold value. Then, the probabilities of a pixel being in the non-water class $\left(P_{n w}\right)$ and the water class $\left(P_{w}\right)$ and the mean pixel values of the non-water class $\left(M_{n w}\right)$ and the water class $\left(M_{w}\right)$ can be obtained by statistical analysis. The between-class variance of the non-water class and water class can be obtained by

$$
\left\{\begin{array}{l}
\sigma^{2}=P_{n w} \cdot\left(M_{n w}-M\right)^{2}+P_{w} \cdot\left(M_{w}-M\right)^{2} \\
M=P_{n w} \cdot M_{n w}+P_{w} \cdot M_{w} \\
P_{n w}+P_{w}=1
\end{array}\right.
$$

where $\sigma$ is the between-class variance of the non-water class and the water class, and $M$ is the mean value of the NDWI image.

Obviously, the parameters in the Equation (5) are functions of the threshold value $t$. The optimal threshold $t^{*}$ can be determined by the between-class variance of the non-water class and the water class using the following equation:

$$
t *=\operatorname{Arg} \underset{a \leq t \leq b}{\operatorname{Max}}\left\{P_{n w} \cdot\left(M_{n w}-M\right)^{2}+P_{w} \cdot\left(M_{w}-M\right)^{2}\right\}
$$

Using Equation (6), the Otsu method selects the threshold by using the rule of maximum between-class variance of the background features (e.g., vegetation, soil, etc.) and water body features. When part of the water body feature is mistakenly classified as a background feature or part of the background feature is wrongly classified as a water body feature, the between-class variance decreases. Equivalently, the greater the variance, the more different the background features and the water body features. Therefore, maximizing the variance between water body features and background features minimizes the probability of misclassification. In other words, a spectral water index model is more suitable for enhancing and extracting water bodies when the NDWI image has high between-class variance.

\subsection{Validation of Land Surface Water Mapping}

The essence of McFeeters's and Xu's NDWIs is to produce water-body-enhanced images. Then, an LSW map can be obtained from these images using threshold image segmentation. Hence, the validity 
of McFeeters's and Xu's NDWIs can be evaluated from an image segmentation perspective. To do this, the between-class variance (BCV), which is $\sigma$ in Equation (5), and the contrast value were selected to evaluate the efficiency of water-body-information enhancement. The contrast value (CV) between water bodies and background features can be obtained by

$$
C V=\left|M_{w}-M_{n w}\right|
$$

On the other hand, a quantitative assessment of the accuracy was conducted for the entire area. The overall accuracy (OA) and the kappa coefficient (Kappa) on the basis of the error matrix [45] were employed to evaluate the accuracy of the LSW map. The kappa coefficient can be obtained by

$$
\text { Kappa }=\frac{P \sum_{i=1}^{n} p_{i i}-\sum_{i=1}^{n}\left(p_{i+} \times p_{+i}\right)}{P^{2}-\sum_{i=1}^{n}\left(p_{i+} \times p_{+i}\right)}
$$

where $p$ is the total number of pixels in the reference data, $p_{i i}$ is the total number of correct pixels of the $i$ th category, $p_{i+}$ is the total number of pixels for the $i$ th category derived from the classified data, $p_{+i}$ is the total number of pixels for the $i$ th category derived from the reference data, and $N$ is the total number of categories.

In this study, we first converted the digital number (DN) values of the selected ALI, TM, and ETM+ images to at-sensor radiance $\left(L_{\lambda}\right)$ using Equation (2). We then converted the at-sensor spectral radiance $\left(L_{\lambda}\right)$ to the TOA reflectance $\left(\rho_{\lambda}\right)$ using Equation (1). Next, we used the TOA reflectance $\left(\rho_{\lambda}\right)$ of the ALI, TM, and ETM+ data in three regions to form twenty-four water-body-enhanced images based on Equations (3) and (4). We then used Equations (5) and (6) to define different image segmentation thresholds and used them to obtain twenty-four LSW maps. Finally, we used the CV, BCV, OA, and Kappa to assess the performance of eleven NDWIs for the LSW maps.

\section{Results}

Eleven NDWI models (Table 2) were used to extract water body information and map LSW from the ALI, TM, and ETM+ data. The results of the water body information detection and LSW maps derived from the ALI remote sensing images were compared with those derived from TM and ETM+ data at the three study sites. In the following section, we focus on analyzing the efficiency of the water body information enhancement and assessing the accuracy of LSW maps derived from the various images of the three regions generated using different NDWI models.

We used TM data acquired on 2 May 2010, and ALI data acquired on 30 September 2010, in the comparative analysis of Region I. The contrast between water body features, including the Three Gorges Reservoir and the Yangtze River, and the background features, such as the Three Gorges Dam and the vegetation, is clear (Figure 2a,h). The subset of data from EO-1 ALI and Landsat TM images were used to generate eight water-body-enhanced images (Figure 2b,d,f,I,k,m,o,q). We used various thresholds (Table 3) applied to eight NDWI images to obtain eight LSW binary maps (Figure 2c,e,g,j,1,n,p,r). Each binary map has two classes: water and non-water areas. Visual interpretation indicates that the eight NDWI images of Region I all clearly show bodies of open water as the result of enhancement. Visual comparison also shows that the main water bodies were detected in the LSW maps (Figure 2c,e,g,j,1,n,p,r) and the boundaries of 
the mapped water bodies match the actual boundaries of the water bodies in the images closely. However, some inaccuracies and omissions occurred, for example, in Figure 2g,j,1,p,r.

Figure 2. Original images and the resulting LSW maps from Landsat TM imagery and EO-1 ALI imagery in Region I. (a) Landsat TM image (2 May 2010) false-color composite (RGB: 752); (b) NDWI calculated from TM Bands 2 and 4; (c) LSW map of NDWI $\mathrm{T}_{2,4}$; (d) NDWI calculated from TM Bands 2 and 5; (e) LSW map of $\mathrm{NDWI}_{\mathrm{T} 2,5}$; (f) NDWI calculated from TM Bands 2 and 7; (g) LSW map of NDWI $\mathrm{N} 2,7_{7}$; (h) EO-1 ALI image (30 September 2010) false-color composite (RGB: 1094); (i) NDWI calculated from ALI Bands 4 and 6; (j) LSW map of NDWI $_{\mathrm{A} 4,6}$; (k) NDWI calculated from ALI Bands 4 and 7; (l) LSW map of $\mathrm{NDWI}_{\mathrm{A} 4,7}$; (m) NDWI calculated from ALI Bands 4 and 8; (n) LSW map of $\mathrm{NDWI}_{\mathrm{A} 4,8} ;(\mathbf{o})$ NDWI calculated from ALI Bands 4 and 9; (p) LSW map of $\mathrm{NDWI}_{\mathrm{A} 4,9}$; (q) NDWI calculated from ALI Bands 4 and 10; (r) LSW map of NDWI $_{\mathrm{A} 4,10}$.

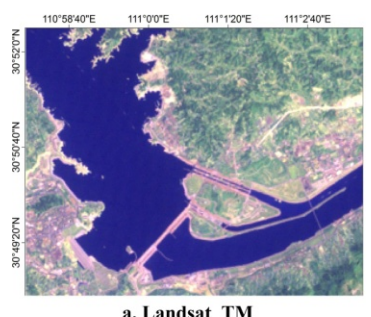

a. Landsat TM

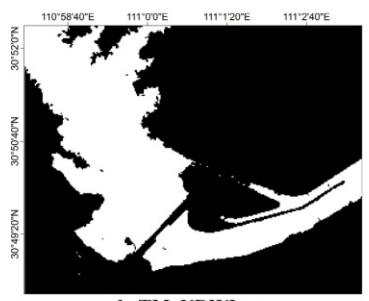

d. TM NDWI 2,5

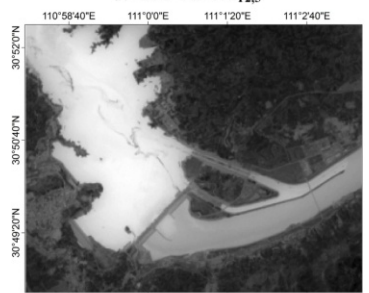

i. ALI $\mathrm{NDWI}_{\mathrm{A4}, 6}$

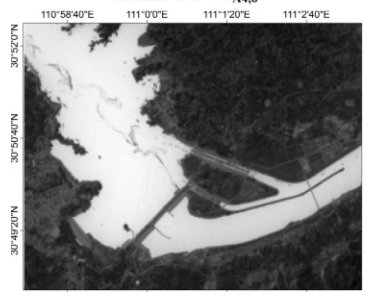

m. ALI NDWI

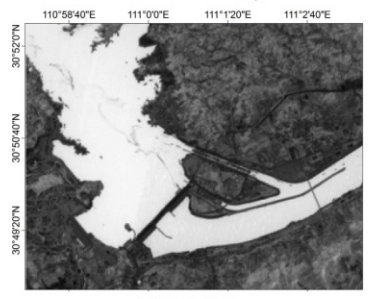

q. ALI $\mathrm{NDWI}_{\mathrm{A}, 10}$

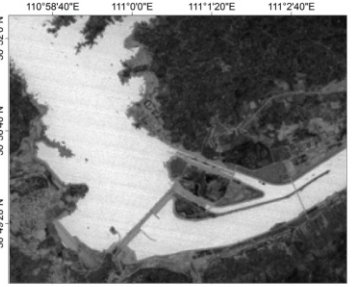

b. TM NDWI $\mathbf{T}_{2,4}$

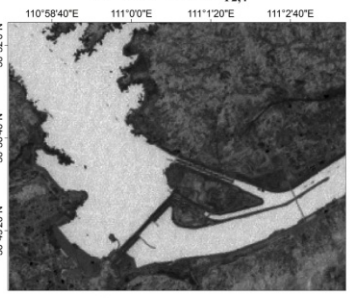

f. TM NDWI $\mathrm{T}_{\mathrm{T} 2,7}$

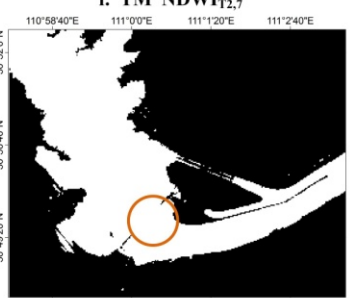

j. LSW map of $\mathrm{NDWI}_{\mathrm{A}, 6}$

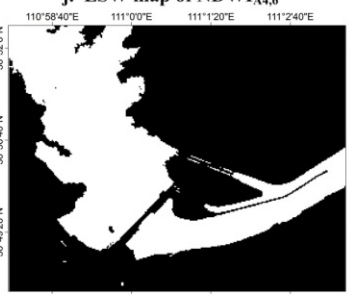

n. LSW map of $\mathrm{NDWI}_{\mathrm{A}, \mathrm{s}}$

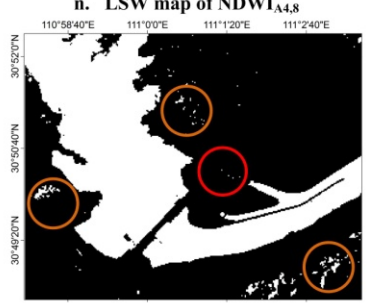

r. LSW map of $\mathrm{NDWI}_{A 4,10}$

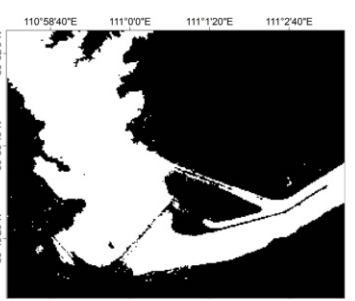

c. LSW map of $\mathrm{NDWI}_{\mathrm{T}, 4}$

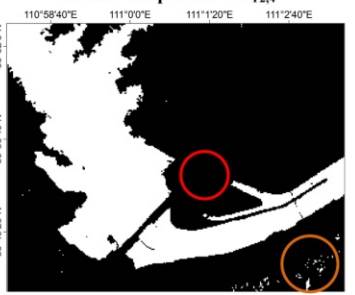

g. LSW map of $\mathrm{NDWI}_{\mathrm{T} 2,7}$

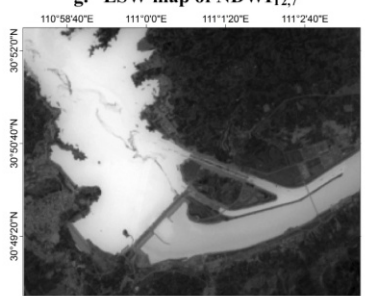

k. ALI NDWI ${ }_{A 4,7}$

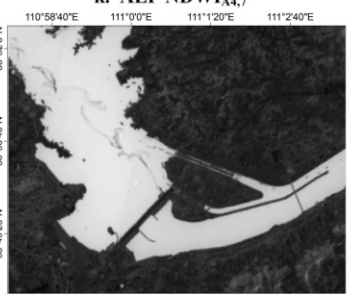

o. ALI NDWI A $49_{9}$

Legend

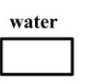

non-water

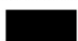

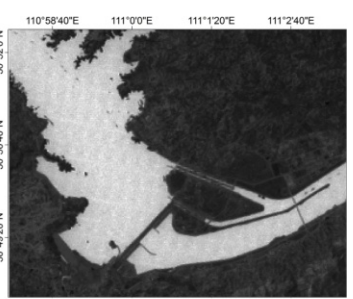

d. TM NDWI $\mathrm{I}_{\mathrm{T}, \mathrm{s}}$

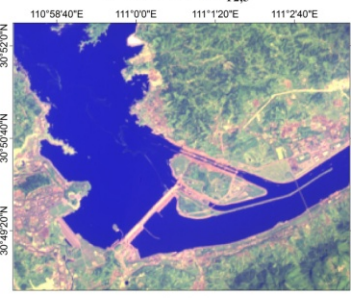

h. EO-1 ALI

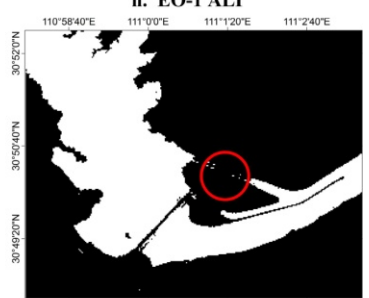

1. LSW map of $\mathrm{NDWI}_{\mathrm{A} 4,7}$

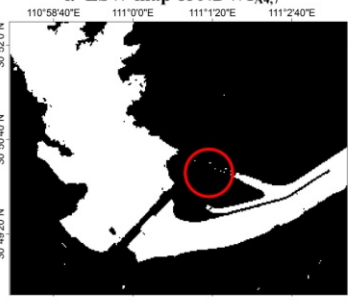

p. LSW map of $\mathrm{NDWI}_{\mathrm{A}, 9}$

N

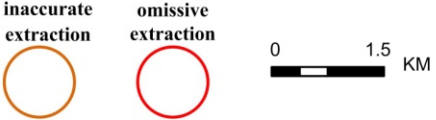


Table 3. NDWI forms, statistical results, associated sensors and bands of the three regions.

\begin{tabular}{|c|c|c|c|c|c|c|c|c|c|}
\hline Place & Sensor & Acquisition Date & NDWI & Threshold & BCV & $\mathrm{CV}$ & $\begin{array}{l}\text { OA } \\
(\%)\end{array}$ & Kappa & $\begin{array}{c}\text { LSW Area } \\
\left(\mathrm{km}^{2}\right)\end{array}$ \\
\hline \multirow{8}{*}{ Region I } & \multirow{3}{*}{$\mathrm{TM}$} & \multirow{3}{*}{ 2010-05-02 } & $\mathrm{NDWI}_{\mathrm{T} 2,4}$ & -0.052 & 0.047 & 0.456 & 93.19 & 0.8440 & 22.89 \\
\hline & & & $\mathrm{NDWI}_{\mathrm{T} 2,5}$ & -0.013 & 0.083 & 0.618 & 96.33 & 0.9133 & 20.85 \\
\hline & & & $\mathrm{NDWI}_{\mathrm{T} 2,7}$ & 0.243 & 0.057 & 0.515 & 95.47 & 0.8939 & 20.77 \\
\hline & \multirow{5}{*}{ ALI } & \multirow{5}{*}{ 2010-09-30 } & $\mathrm{NDWI}_{\mathrm{A} 4,6}$ & -0.294 & 0.026 & 0.341 & 94.23 & 0.8673 & 22.43 \\
\hline & & & $\mathrm{NDWI}_{\mathrm{A} 4,7}$ & -0.265 & 0.043 & 0.438 & 95.54 & 0.8962 & 21.57 \\
\hline & & & $\mathrm{NDWI}_{\mathrm{A} 4,8}$ & 0.166 & 0.090 & 0.638 & 95.89 & 0.9040 & 21.33 \\
\hline & & & $\mathrm{NDWI}_{\mathrm{A} 4,9}$ & 0.134 & 0.111 & 0.713 & 96.76 & 0.9235 & 20.73 \\
\hline & & & $\mathrm{NDWI}_{\mathrm{A} 4,10}$ & 0.289 & 0.078 & 0.592 & 95.86 & 0.9034 & 21.34 \\
\hline \multirow{8}{*}{ Region II } & \multirow{3}{*}{$\mathrm{TM}$} & \multirow{3}{*}{ 2005-09-09 } & $\mathrm{NDWI}_{\mathrm{T} 2,4}$ & -0.093 & 0.031 & 0.522 & 95.18 & 0.7819 & 9.61 \\
\hline & & & $\mathrm{NDWI}_{T 2,5}$ & 0.054 & 0.071 & 0.768 & 95.94 & 0.8097 & 9.00 \\
\hline & & & $\mathrm{NDWI}_{\mathrm{T} 2,7}$ & 0.406 & 0.036 & 0.531 & 95.43 & 0.7902 & 9.37 \\
\hline & \multirow{5}{*}{ ALI } & \multirow{5}{*}{$2005-10-21$} & $\mathrm{NDWI}_{\mathrm{A} 4,6}$ & -0.201 & 0.005 & 0.197 & 96.19 & 0.8231 & 9.16 \\
\hline & & & $\mathrm{NDWI}_{\mathrm{A} 4,7}$ & -0.173 & 0.008 & 0.240 & 96.49 & 0.8349 & 8.90 \\
\hline & & & $\mathrm{NDWI}_{\mathrm{A} 4,8}$ & 0.214 & 0.015 & 0.302 & 96.56 & 0.8372 & 8.84 \\
\hline & & & $\mathrm{NDWI}_{\mathrm{A} 4,9}$ & 0.243 & 0.018 & 0.325 & 97.73 & 0.8818 & 7.25 \\
\hline & & & $\mathrm{NDWI}_{\mathrm{A} 4,10}$ & 0.295 & 0.013 & 0.245 & 96.53 & 0.8337 & 8.61 \\
\hline \multirow{8}{*}{ Region III } & \multirow{3}{*}{ ETM+ } & \multirow{3}{*}{ 2003-03-29 } & $\mathrm{NDWI}_{\mathrm{E} 2,4}$ & 0.242 & 0.019 & 0.288 & 87.72 & 0.7050 & 22.21 \\
\hline & & & $\mathrm{NDWI}_{\mathrm{E} 2,5}$ & 0.256 & 0.030 & 0.378 & 91.60 & 0.7862 & 19.36 \\
\hline & & & $\mathrm{NDWI}_{\mathrm{E} 2,7}$ & 0.410 & 0.023 & 0.315 & 90.80 & 0.7671 & 19.60 \\
\hline & \multirow{5}{*}{ ALI } & \multirow{5}{*}{ 2003-03-29 } & $\mathrm{NDWI}_{\mathrm{A} 4,6}$ & -0.331 & 0.018 & 0.294 & 91.33 & 0.7752 & 19.53 \\
\hline & & & $\mathrm{NDWI}_{\mathrm{A} 4,7}$ & -0.313 & 0.023 & 0.334 & 92.36 & 0.8042 & 19.03 \\
\hline & & & $\mathrm{NDWI}_{\mathrm{A} 4,8}$ & 0.122 & 0.033 & 0.393 & 93.62 & 0.8348 & 18.54 \\
\hline & & & $\mathrm{NDWI}_{\mathrm{A} 4,9}$ & 0.035 & 0.040 & 0.416 & 93.88 & 0.8432 & 19.03 \\
\hline & & & $\mathrm{NDWI}_{\mathrm{A} 4,10}$ & 0.188 & 0.031 & 0.367 & 93.12 & 0.8241 & 19.11 \\
\hline
\end{tabular}

We then used the $\mathrm{CV}$ and $\mathrm{BCV}$ to assess the potential of eight NDWI models for water body information enhancement and the adaptability of image segmentation. The indexes OA and Kappa were used to evaluate the performance of LSW maps based on the eight NDWI images in Region I.

First, we used the CV index to analyze the water body information enhancement of the eight NDWI images. The results of this quantitative assessment of Region I (Table 3) show that the maximum $\mathrm{CV}$ value of the five NDWI images derived from the ALI sensor is $0.713\left(\mathrm{NDWI}_{\mathrm{A} 4,9}\right)$, followed by $0.638\left(\mathrm{NDWI}_{\mathrm{A} 4,8}\right), 0.592\left(\mathrm{NDWI}_{\mathrm{A} 4,10}\right), 0.438\left(\mathrm{NDWI}_{\mathrm{A} 4,7}\right)$, and $0.341\left(\mathrm{NDWI}_{\mathrm{A} 4,6}\right)$. According to the contrast method [34], the higher the CV value the better the enhancement of the water body features. These results mean that the combination of the green wavelength band (Band 4, 0.520-0.605 $\mu \mathrm{m}$ ) and the SWIR wavelength band (Band 9, 1.550-1.750 $\mu \mathrm{m}$ ) is the best indicator for water body information enhancement when the ALI data are employed to enhance water body information. Then, we used $\mathrm{BCV}$ to assess the image segmentation adaptability of the five NDWI images. Table 3 shows that the highest $\mathrm{BCV}$ value of the five ALI NDWI images was that of $\mathrm{NDWI}_{\mathrm{A} 4,9}(0.111)$, followed by $\mathrm{NDWI}_{\mathrm{A} 4,8}(0.090), \mathrm{NDWI}_{\mathrm{A} 4,10}(0.078), \mathrm{NDWI}_{\mathrm{A} 4,7}(0.043)$, and $\mathrm{NDWI}_{\mathrm{A} 4,6}(0.026)$. By the Otsu 
criterion, we conclude that the NDWI model based on the $0.525-0.605 \mu \mathrm{m}$ green band and the $1.550-1.750 \mu \mathrm{m}$ SWIR band of the ALI sensor is most suitable for image segmentation. Hence, the NDWI model using the green band and the 1.550-1.750 $\mu \mathrm{m}$ SWIR band of the ALI sensor, namely, $\mathrm{NDWI}_{\mathrm{A} 4,9}$, is the best indicator for the delineation of water body information from a comprehensive view of water-body information enhancement and image segmentation. A secondary choice is $\mathrm{NDWI}_{\mathrm{A} 4,8}$, followed by $\mathrm{NDWI}_{\mathrm{A} 4,10}, \mathrm{NDWI}_{\mathrm{A} 4,7}$, and $\mathrm{NDWI}_{\mathrm{A} 4,6}$. For the TM sensor in Region I, Table 3 indicates that the combination of the green channel (Band 2, 0.520-0.600 $\mu \mathrm{m}$ ) and the SWIR channel (Band 5, 1.550-1.750 $\mu \mathrm{m}$ ), namely, $\mathrm{NDWI}_{\mathrm{T} 2,5}$, is the best indicator for water-body information delineation, followed by $\mathrm{NDWI}_{\mathrm{T} 2,7}$ and $\mathrm{NDWI}_{\mathrm{T} 2,4}$. This is consistent with the results based on the analysis of laboratory spectral data [38].

We next used the OA and Kappa to quantitatively assess the accuracy of the eight NDWI LSW maps of Region I. This quantitative assessment was performed in three steps. First, the reference data were selected. As water bodies and the LSW distribution move and change over time $[11,40]$, it is best to use high-spatial-resolution data or a multispectral image taken at the same time as the reference data to minimize any time-dependent effects. The acquisition dates of the ALI and TM data used in Region I were September 2010, and May 2010, respectively. Thus, we selected the ALI panchromatic image, which has $10 \mathrm{~m}$ spatial resolution and was acquired at the same time as the ALI multispectral images, as the reference data to assess the accuracy of the five LSW maps derived from the ALI sensor. We used the false-color composite image acquired at the same time as TM, i.e., RGB752, which best enhances the water body information [11], as the reference data to evaluate the accuracy of the three LSW maps resulting from the Landsat TM images. Second, the selected reference data were visually interpreted by one person and checked by two people to produce the reference data; all three people were familiar with the study area. Next, we used the pixel-by-pixel comparison method $[34,46]$ to assess the accuracy of these LSW maps using the reference data. Then, error matrixes were created to obtain OA and Kappa. Table 3 shows that the accuracy is relatively stable among the five ALI LSW maps, with the maps of $\mathrm{NDWI}_{\mathrm{A} 4,6}, \mathrm{NDWI}_{\mathrm{A} 4,7}, \mathrm{NDWI}_{\mathrm{A} 4,8}, \mathrm{NDWI}_{\mathrm{A} 4,9}$, and $\mathrm{NDWI}_{\mathrm{A} 4,10}$ having $\mathrm{OA}$ of $94.23 \%, 95.54 \%, 95.89 \%, 96.67 \%$, and 95.86\%, respectively, and Kappa of 0.8673, 0.8962, 0.9040, 0.9235, and 0.9034, respectively. The quantitative assessment results (Table 3) show that $\mathrm{NDWI}_{\mathrm{A} 4,9}$ had the highest $\mathrm{OA}$ and Kappa values; next highest were $\mathrm{NDWI}_{\mathrm{A} 4,8}, \mathrm{NDWI}_{\mathrm{A} 4,10}, \mathrm{NDWI}_{\mathrm{A} 4,7}$, and $\mathrm{NDWI}_{\mathrm{A} 4,6}$. The maximum values of OA and Kappa for the TM sensor come from $\mathrm{NDWI}_{\mathrm{T} 2,5}$, followed by $\mathrm{NDWI}_{\mathrm{T} 2,7}$, and $\mathrm{NDWI}_{\mathrm{T} 2,4}$. The accuracy of LSW maps as assessed using OA and Kappa are consistent with the results of the analysis based on CV and BCV. The areas of LSW in Region I identified from the TM data were $22.89 \mathrm{~km}^{2}$ (as measured by $\left.\mathrm{NDWI}_{\mathrm{T} 2,4}\right), 20.85 \mathrm{~km}^{2}\left(\mathrm{NDWI}_{\mathrm{T} 2,5}\right.$ ), or $20.77 \mathrm{~km}^{2}\left(\mathrm{NDWI}_{\mathrm{T} 2,7}\right)$ (Table 3). The LSW areas derived from the ALI data were $22.43 \mathrm{~km}^{2}$ $\left(\mathrm{NDWI}_{\mathrm{A} 4,6}\right), 21.57 \mathrm{~km}^{2}\left(\mathrm{NDWI}_{\mathrm{A} 4,7}\right), 21.33 \mathrm{~km}^{2}\left(\mathrm{NDWI}_{\mathrm{A} 4,8}\right), 20.73 \mathrm{~km}^{2}\left(\mathrm{NDWI}_{\mathrm{A} 4,9}\right)$, or $21.34 \mathrm{~km}^{2}$ $\left(\mathrm{NDWI}_{\mathrm{A} 4,10}\right)$.

Based on the above analyses, we conclude that the normalized difference water index based on the green band (i.e., Band 4 of ALI or Band 2 of TM) and the SWIR band (i.e., Band 9 of ALI or Band 5 of TM) with the spectrum region of $1.550-1.750 \mu \mathrm{m}$, that is, Xu's NDWI or MNDWI, is the optimal choice for water body information enhancement and LSW mapping. 
Figure 3. Original images and the LSW map results from Landsat TM imagery and EO-1 ALI imagery in Region II. (a) Landsat TM image (9 September 2005) false-color composite (RGB: 432); (b) NDWI calculated from TM Bands 2 and 4; (c) LSW map of $\mathrm{NDWI}_{\mathrm{T} 2,4}$; (d) NDWI calculated from TM Bands 2 and 5; (e) LSW map of NDWI $\mathrm{N}_{2,5}$; (f) NDWI calculated from TM Bands 2 and 7; (g) LSW map of $\mathrm{NDWI}_{\mathrm{T} 2,7}$; (h) EO-1 ALI image (21 October 2005) false-color composite (RGB: 965); (i) NDWI calculated from ALI Bands 4 and 6; (j) LSW map of NDWI $_{\mathrm{A} 4,6} ;(\mathbf{k})$ NDWI calculated from ALI Bands 4 and 7; (l) LSW map of $\mathrm{NDWI}_{\mathrm{A} 4,7} ;$ (m) NDWI calculated from ALI Bands 4 and 8; (n) LSW map of NDWI $_{\mathrm{A} 4,8}$; (o) NDWI calculated from ALI Bands 4 and 9; (p) LSW map of $\mathrm{NDWI}_{\mathrm{A} 4,9} ;(\mathbf{q})$ NDWI calculated from ALI Bands 4 and 10; (r) LSW map of NDWI $\mathrm{N}_{\mathrm{A}, 10}$.

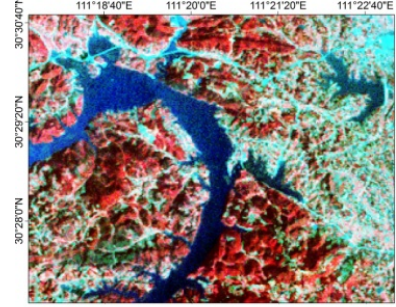

a. Landsat TM

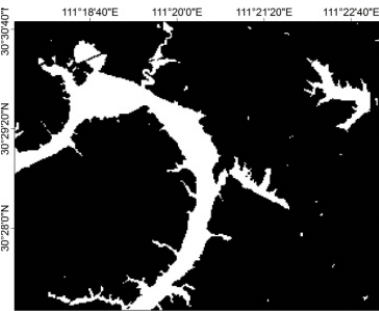

e. LSW map of $\mathrm{NDWI}_{\mathrm{T} 2}$

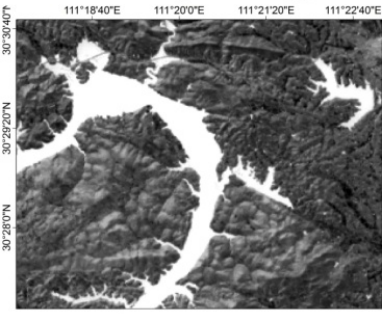

i. ALI NDWI N4,

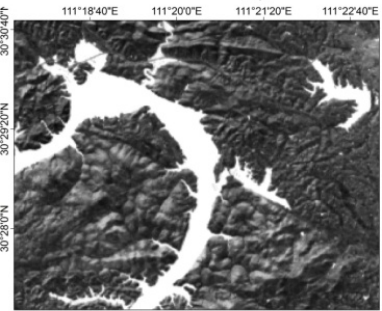

m. ALI NDWI

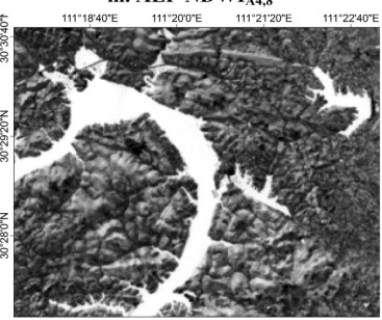

q. ALI NDWI A $_{4,10}$

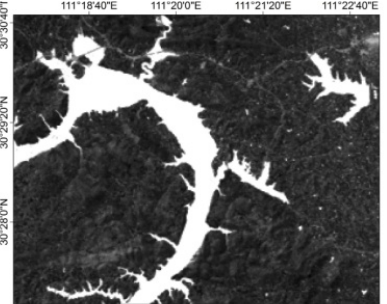

b. TM NDWI $\mathrm{T}_{\mathrm{T}, 4}$

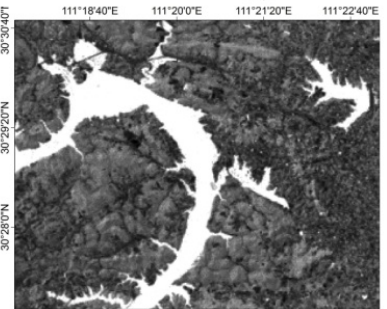

f. TM NDWI $\mathbf{I}_{\mathrm{T}, 7}$

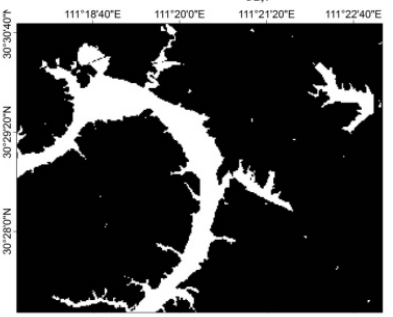

j. LSW map of NDWI

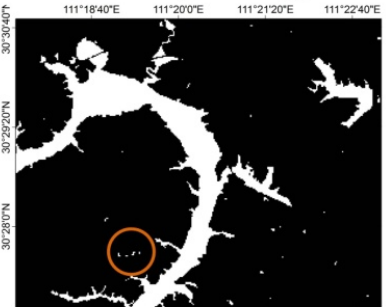

n. LSW map of $\mathrm{NDWI}_{\mathrm{A} 4,8}$

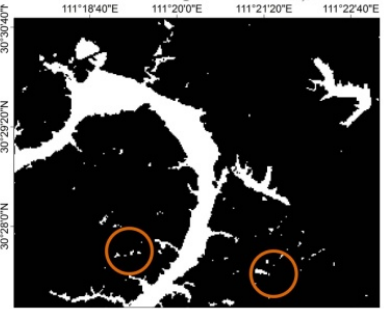

r. LSW map of $\mathrm{NDWI}_{\mathrm{A}, 10}$

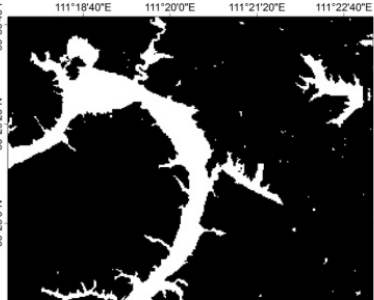

c. LSW map of $\mathrm{NDWI}_{\mathrm{T} 2,4}$

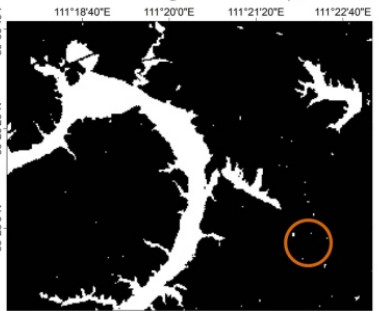

g. LSW map of $\mathrm{NDWI}_{\mathrm{T} 2,7}$

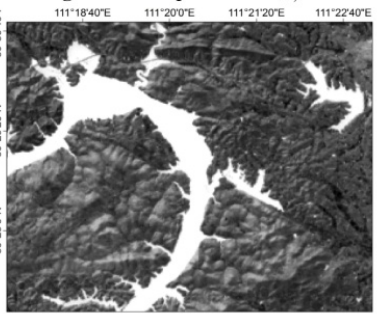

k. ALI NDWI A $_{4,7}$

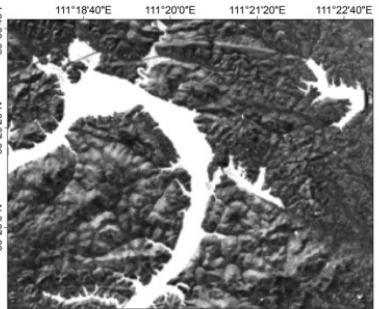

o. ALI NDWI A4,

Legend

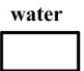

non-wate

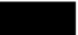

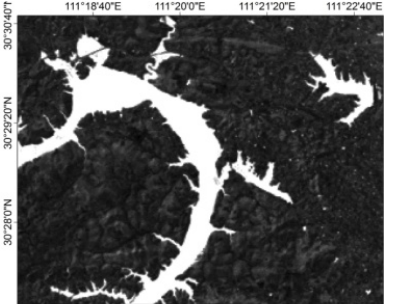

d. $T M$ NDWI $_{T 2,5}$

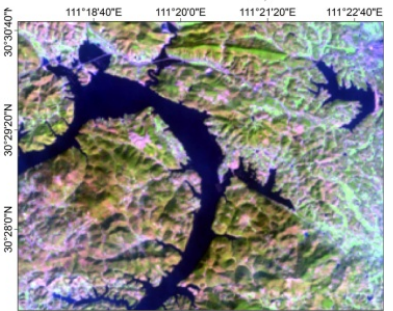

h. EO-1 ALI

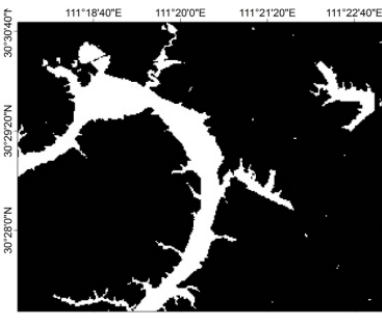

I. LSW map of NDWI

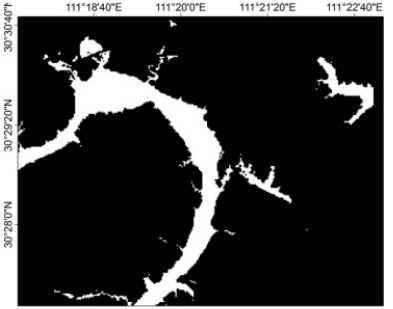

p. LSW map of $\mathrm{NDWI}_{\mathrm{A} 4,9}$

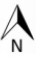

inaccurate omissive

extraction extraction
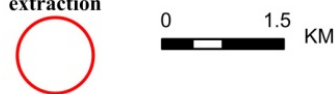
Figure 4. Original images and the LSW map results from Landsat ETM+ imagery and EO-1 ALI imagery in Region III. (a) Landsat ETM+ image (29 March 29 2003) false-color composite (RGB:753); (b) NDWI calculated from ETM+ Bands 2 and 4; (c) LSW map of $\mathrm{NDWI}_{\mathrm{E} 2,4}$; (d) NDWI calculated from ETM+ Bands 2 and 5; (e) LSW map of NDWI $\mathrm{N} 2,5$; (f) NDWI calculated from ETM+ Bands 2 and 7; (g) LSW map of NDWI $\mathrm{E}_{2,7}$; (h) EO-1 ALI image (29 March 29 2003) false-color composite (RGB: 965); (i) NDWI calculated from ALI Bands 4 and 6; (j) LSW map of NDWI $\mathrm{A}_{4,6}$; (k) NDWI calculated from ALI Bands 4 and 7; (l) LSW map of NDWI $_{\mathrm{A} 4,7} ;$ (m) NDWI calculated from ALI Bands 4 and 8; (n) LSW map of NDWI $_{\mathrm{A} 4,8}$; (o) NDWI calculated from ALI Bands 4 and 9; (p) LSW map of $\mathrm{NDWI}_{\mathrm{A} 4,9} ;(\mathbf{q})$ NDWI calculated from ALI Bands 4 and 10; (r) LSW map of NDWI $\mathrm{N}_{\mathrm{A}, 10}$.

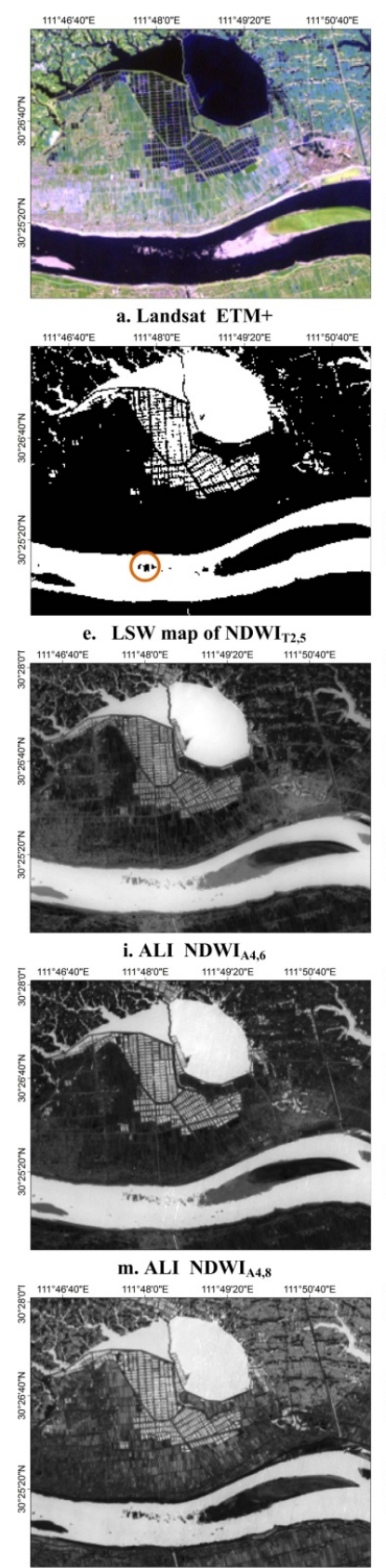

q. ALI NDWI A4,10
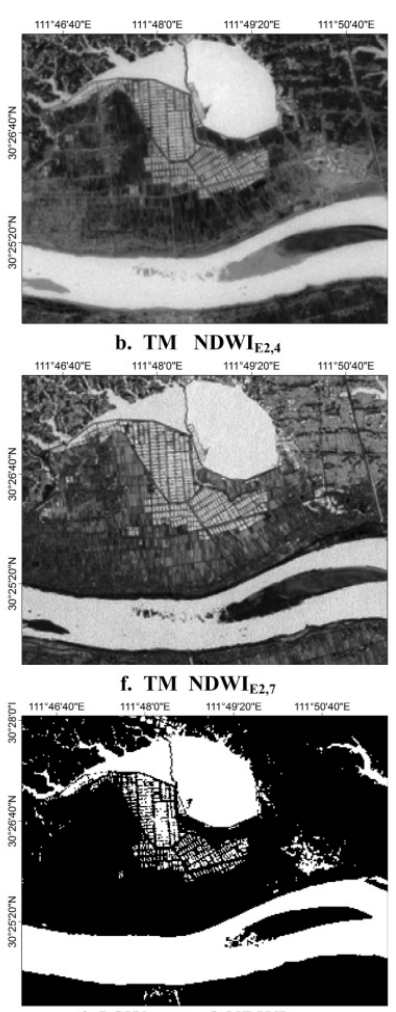

i. LSW map of $\mathrm{NDWI}_{\mathrm{A} 4,6}$

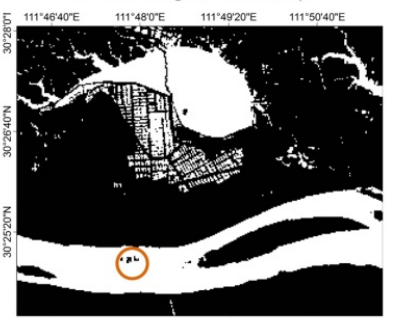

n. LSW map of $\mathrm{NDWI}_{\mathrm{A} 4,8}$

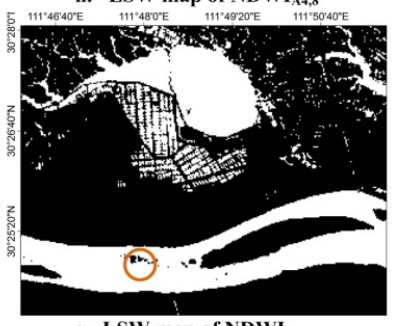

q. LSW map of $\mathrm{NDWI}_{\mathrm{A} 4,10}$

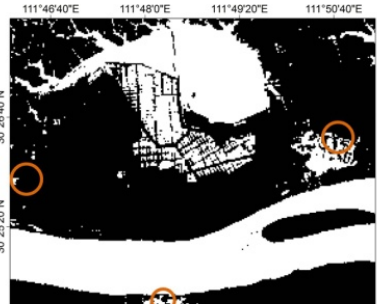

c. LSW map of NDWI 2 2,4

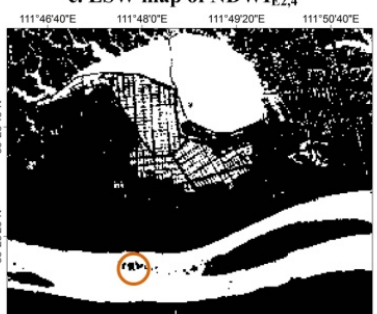

g. LSW map of $\mathrm{NDWI}_{\mathrm{E} 2,7}$
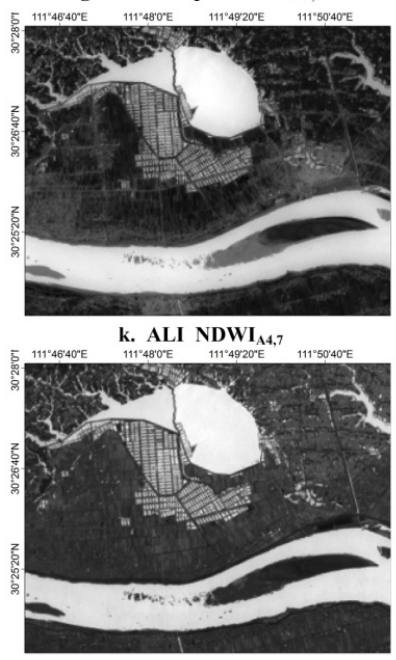

o. ALI NDWI

Legend

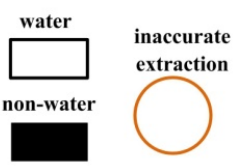

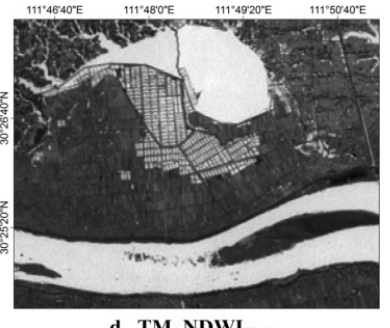

d. TM NDWI $\mathbf{E}_{\mathrm{E}, 5}$

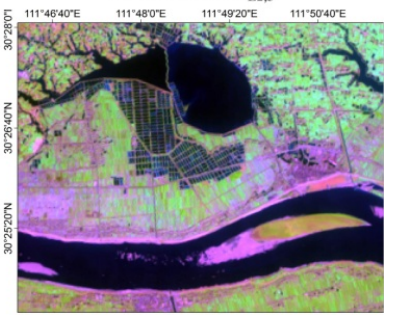

h. EO-1 ALI

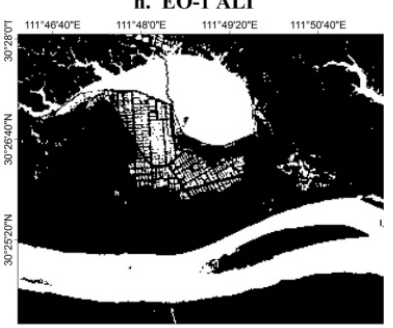

I. LSW map of $\mathrm{NDWI}_{\mathrm{A}, 7}$

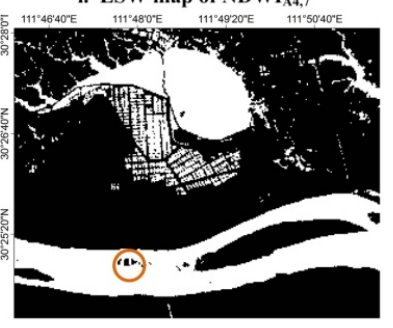

p. LSW map of $\mathrm{NDWI}_{\mathrm{A}, 9}$
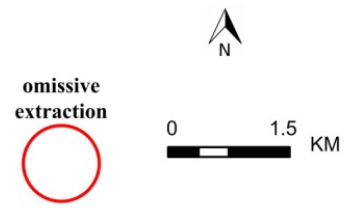
EO-1 ALI images from 21 October 2005, and Landsat TM images from 9 September 2005, were used in Region II. The contrast between water features such as the Baifengxi and Gaobazhou Reservoirs and vegetation features is clear (Figure 3a,h). Visual interpretation shows that the eight surface water maps (Figure 3c,e,g,j,l,n,p,r) matched the actual distribution of water closely. We also selected the ALI panchromatic image and the TM RGB752 image as the reference data to evaluate the accuracy of the LSW maps results because the acquisition dates of the selected ALI and TM data were different. The results of the quantitative assessment (Table 3) show that the $\mathrm{NDWI}_{\mathrm{A} 4,9}$ gives maximum values of $\mathrm{CV}, \mathrm{BCV}, \mathrm{OA}$, and Kappa for the five ALI NDWIs in Region II; next best are $\mathrm{NDWI}_{\mathrm{A} 4,8}$, $\mathrm{NDWI}_{\mathrm{A} 4,10}, \mathrm{NDWI}_{\mathrm{A} 4,7}$, and $\mathrm{NDWI}_{\mathrm{A} 4,6}$. In the case of the $\mathrm{TM}$ sensor, the order of preference is $\mathrm{NDWI}_{\mathrm{T} 2,5}, \mathrm{NDWI}_{\mathrm{T} 2,7}$, and $\mathrm{NDWI}_{\mathrm{T} 2,4}$. The results of the quantitative analysis of Region II replicated the performance of the eight NDWI models in Region I. The LSW area in Region II was measured as 9.61 $\mathrm{km}^{2}$ by $\mathrm{NDWI}_{\mathrm{T} 2,4}, 9.00 \mathrm{~km}^{2}$ by $\mathrm{NDWI}_{\mathrm{T} 2,5}$, and $9.37 \mathrm{~km}^{2}$ by $\mathrm{NDWI}_{\mathrm{T} 2,7}$. Using ALI data, we obtained LSW areas of $9.16 \mathrm{~km}^{2}\left(\mathrm{NDWI}_{\mathrm{A} 4,6}\right), 8.92 \mathrm{~km}^{2}\left(\mathrm{NDWI}_{\mathrm{A} 4,7}\right), 8.84 \mathrm{~km}^{2}\left(\mathrm{NDWI}_{\mathrm{A} 4,8}\right), 7.25 \mathrm{~km}^{2}$ $\left(\mathrm{NDWI}_{\mathrm{A} 4,9}\right)$, and $8.61 \mathrm{~km}^{2}\left(\mathrm{NDWI}_{\mathrm{A} 4,10}\right)$ (Table 3).

We used ALI and ETM+ data both acquired on 29 March 2003, for the comparative analysis in Region III. The contrast between the water features, including the Yangtze River and Dong Lake, and the background features, such as vegetation, sandbanks, cities and towns, is clear (Figure 4a,h). The EO-1 ALI data and Landsat ETM+ images were used to form eight different NDWI images (Figure $4 \mathrm{~b}, \mathrm{~d}, \mathrm{f}, \mathrm{i}, \mathrm{k}, \mathrm{m}, \mathrm{o}, \mathrm{q}$ ) of Region III. Visual interpretation indicates that the eight NDWI images all clearly show open water body features as the result of enhancement. The main LSW distributions were detected in all eight LSW maps (Figure 4c,e,g,j,1,n,p,r). We selected the panchromatic images of ALI and ETM+ as the reference data because the ALI and TM data were taken on the same day. The quantitative assessment results (Table 3) show that the highest $\mathrm{CV}, \mathrm{BCV}, \mathrm{OA}$, and Kappa for the five ALI NDWIs in Region III also come from $\mathrm{NDWI}_{\mathrm{A} 4,9}$, followed by $\mathrm{NDWI}_{\mathrm{A} 4,8}, \mathrm{NDWI}_{\mathrm{A} 4,10}, \mathrm{NDWI}_{\mathrm{A} 4,7}$, and $\mathrm{NDWI}_{\mathrm{A} 4,6}$. The ETM+ sensor yielded results in the following order: $\mathrm{NDWI}_{\mathrm{E} 2,5}, \mathrm{NDWI}_{\mathrm{E} 2,7}$, and $\mathrm{NDWI}_{\mathrm{E} 2,4}$. The results of the quantitative analysis of Region III were the same as in Regions I and II. The total areas covered by water bodies in Region III derived from the ETM + data were $22.21 \mathrm{~km}^{2}$ $\left(\mathrm{NDWI}_{\mathrm{E} 2,4}\right), 19.36 \mathrm{~km}^{2}\left(\mathrm{NDWI}_{\mathrm{E} 2,5}\right)$, and $19.60 \mathrm{~km}^{2}\left(\mathrm{NDWI}_{\mathrm{E} 2,7}\right)$, while those derived from the ALI data were $19.53 \mathrm{~km}^{2}\left(\mathrm{NDWI}_{\mathrm{A} 4,6}\right), 19.03 \mathrm{~km}^{2}\left(\mathrm{NDWI}_{\mathrm{A} 4,7}\right), 18.54 \mathrm{~km}^{2}\left(\mathrm{NDWI}_{\mathrm{A} 4,8}\right), 19.03 \mathrm{~km}^{2}\left(\mathrm{NDWI}_{\mathrm{A} 4,9}\right)$, and $19.11 \mathrm{~km}^{2}\left(\mathrm{NDWI}_{\mathrm{A} 4,10}\right)$ (Table 3$)$.

\section{Discussions}

The results at the three test regions (Table 3) show that the overall accuracy of LSW maps is greater than $85 \%$ and the overall Kappa coefficient is greater than 0.70 . This indicates that there were some misclassifications in the LSW maps (i.e., Figures 2g,j,p,r, 3g,n,r, and 4c,e,g,j,n,p,r). These misclassifications are caused by overestimating in small water bodies (e.g., farm ponds) and underestimating in the slender river channels with mixed pixels (e.g., a land-water border within one pixel). This can be address using spectral unmixing [47].

One factor that may significantly affect the efficiency of LSW maps using the normalized difference water index is the threshold selection. The threshold for LSW mapping will be influenced by the subjective judgment of the user [20]. To avoid the subjectivity of the threshold selection, Otsu's 
threshold segmentation method was used to obtain the image partition thresholds in this paper. However, for large-scale regional LSW mapping, one threshold is not sufficient to extract all the water bodies from the background due to spatially varying spectral contrast. Therefore, a multi-threshold image segmentation method is required when the methods discussed in this paper are used in large-scale regional LSW mapping. Another major factor is that there is no ground-truth water body surface distribution and acreage information. To address this problem, we selected TM data (2 May 2010) and ALI data (30 September 2010) at dates during the wet (rainy) season of the study area to comparatively analyze in Region I. Importantly, the Three Gorges Reservoir water levels on 2 May 2010 and 30 September 2010, were approximately equal. That means that the water body surface distribution and acreage information of the two times of selected data are also approximately equal. Therefore, we can select the panchromatic image with the higher spatial resolution or the multispectral false-color composite images acquired at the same time as the "true" water body surface distribution and acreage information for Region I. In Region II, we selected TM (9 September 2005) and ALI (21 October 2005). The Gaobazhou Reservoir downstream had similar water levels on 9 September 2005 and 21 October 2005, which means that the water body surface distribution and acreage information at the two times of selected data are also similar. Therefore, we also can selected the panchromatic image or the multispectral false-color composite images as the "true" water body surface distribution and acreage information for Region II. In Region III, we selected ALI data and ETM+ data acquired on 29 March 2003. We also selected the panchromatic image with the higher spatial resolution as the "true" water body surface distribution and acreage information for Region III. Still, the true surface water distribution information is preferable to this estimate if that information can be obtained.

We also noted that the TM, ETM+, and ALI sensors all have similar spectral range bands, such as Band 2 of TM/ETM+ vs. Band 4 of ALI, Band 5 of TM/ETM+ vs. Band 9 of ALI, and Band 7 of $\mathrm{TM} / \mathrm{ETM}+$ vs. Band 10 of ALI. These bands were all employed in different NDWI models (Table 2 and Table 3). Consequently, it is necessary to analyze the performance of different NDWI models based on the similar spectral range bands of the TM, ETM+, and ALI sensors. The ALI and ETM+ data used in Region III acquired on the same time. For this purpose, we first compared two NDWI models, namely $\mathrm{NDWI}_{\mathrm{A} 4,9}$ and $\mathrm{NDWI}_{\mathrm{E} 2,5}$, based on the green channel and SWIR channel with the spectral range of 1.550-1.750 $\mu \mathrm{m}$ in Region III. The OA and Kappa of $\mathrm{NDWI}_{\mathrm{A} 4,9}$ are higher than those of $\mathrm{NDWI}_{\mathrm{E} 2,5}$ in Region III (Table 3). Then, we compared $\mathrm{NDWI}_{\mathrm{A} 4,10}$ and $\mathrm{NDWI}_{\mathrm{E} 2,7}$, using the green channel and the SWIR channel with the spectral range of 2.080-2.350 $\mu \mathrm{m}$. The OA and Kappa of $\mathrm{NDWI}_{\mathrm{A} 4,10}$ are higher than those of $\mathrm{NDWI}_{\mathrm{E} 2,7}$ in Region III (Table 3). There were two reasons that the ALI data performed better on LSW mapping than did the ETM+ data, despite their common SWIR spectral range. First, the ALI data have higher signal-to-noise ratios (SNRs) than the ETM+ data: the SNRs of the ALI data range from 100 to 300, while the ETM+ manages SNRs of just 15-50 [48]. Second, the ALI data have higher inherent data precision than ETM+ data because the ALI push-broom system offers significant radiometric improvement over ETM+ [49]. This means that the ALI data will perform better in LSW mapping than ETM+ data when they are employed using the spectral water index with the similar spectral range. However, the coverage of the ALI data is only one-fifth of that of TM or ETM+, which means that the ALI data are not suitable for large-scale LSW 
mapping. Research on the Landsat-8 Operational Land Imager (OLI) LSW mapping method based on the spectral water index method is an important direction for development.

\section{Conclusions}

We calculated eleven different normalized difference water indexes (NDWIs) based on the green, near-infrared (NIR), and shortwave-infrared (SWIR) bands of Earth Observation-1 (EO-1) Advanced Land Imager (ALI), Landsat Thematic Mapper (TM), and Landsat Enhanced Thematic Mapper Plus $($ ETM+) sensors. The results of this quantitative analysis show that (1) the NDWI model based on the green band (Band 4: 0.520-0.605 $\mu \mathrm{m}$ ) and the SWIR band (Band 9: 1.550-1.750 $\mu \mathrm{m}$ ) of the ALI sensor, namely $\mathrm{NDWI}_{\mathrm{A} 4,9}$, is the best indicator for land surface water (LSW) mapping; (2) using Bands 4 and 9 of the ALI sensor to produce an LSW map will obtain the best effect, followed by Bands 4 and $8(1.200-1.300 \mu \mathrm{m})$, Bands 4 and $10(2.080-2.350 \mu \mathrm{m})$, Bands 4 and $7(0.845-0.890 \mu \mathrm{m})$, and Bands 4 and $6(0.775-0.805 \mu \mathrm{m})$.

The results of this paper also show that Xu's NDWI performs better than McFeeters's NDWI on water body information enhancement and LSW mapping, confirming previous results [34,38]. The indexes using the green band $(0.520-0.605 \mu \mathrm{m})$ and the SWIR band $(1.550-1.750 \mu \mathrm{m})$, that is Xu's NDWI, are the most efficient indices for detecting water body information and for mapping water bodies. Specifically for the EO-1 ALI sensors, we recommend $\mathrm{NDWI}_{\mathrm{A} 4,9}$, for detection of LSW body features, such as open water body information extracting, flood disaster monitoring, flood disaster risk assessing, wetland mapping, LSW mapping, and identification of other water body features.

\section{Acknowledgments}

This paper is financially supported by the National Natural Science Foundation of China (No: 41101516, 41201413, 61203373, and 91024008) and the Industry development special project of China's National Development and Reform Commission (2012 satellite and applications industry development project). We are indebted to U.S. Geological Survey server (http://earthexplorer.usgs.gov/) for preprocessing and providing the EO-1 ALI, Landsat TM, and Landsat ETM+ data used in this manuscript. We also thank Dan Xiao (Guizhou University of Finance and Economics) for embellishing figures in the manuscript. The authors wish to thank anonymous reviewers for their very constructive suggestions and comments.

\section{Conflicts of Interest}

The authors declare no conflict of interest.

\section{References}

1. Behera, M.D.; Chitale, V.S.; Shaw, A.; Roy, P.S.; Murthy, M.S.R. Wetland monitoring, serving as an index of land use change-a study in Samaspur Wetlands, Uttar Pradesh, India. J. Indian Soc. Remote Sens. 2012, 40, 287-297. 
2. Bortels, L.; Chan, J.C.W.; Merken, R.; Koedam, N. Long-term monitoring of wetlands along the Western-Greek Bird Migration Route using Landsat and ASTER satellite images: Amvrakikos Gulf (Greece). J. Nat. Conserv. 2011, 19, 215-223.

3. Davranche, A.; Lefebvre, G.; Poulin, B. Wetland monitoring using classification trees and SPOT-5 seasonal time series. Remote Sens. Environ. 2010, 114, 552-562.

4. Schumann, G.J.P.; Neal, J.C.; Mason, D.C.; Bates, P.D. The accuracy of sequential aerial photography and SAR data for observing urban flood dynamics, a case study of the UK summer 2007 floods. Remote Sens. Environ. 2011, 115, 2536-2546.

5. Sheng, Y.; Gong, P.; Xiao, Q. Quantitative dynamic flood monitoring with NOAA AVHRR. Int. J. Remote Sens. 2001, 22, 1709-1724.

6. Zhang, J.; Zhou, C.; Xu, K.; Watanabea, M. Flood disaster monitoring and evaluation in China. Environ. Hazards. 2002, 4, 33-43.

7. Qi, H.; Altinakar, M.S. Simulation-based decision support system for flood damage assessment under uncertainty using remote sensing and census block information. Nat. Hazards. 2011, 59, 1125-1143.

8. Stephensa, E.M.; Batesa, P.D.; Freera, J.E.; Masonb, D.C. The impact of uncertainty in satellite data on the assessment of flood inundation models. J. Hydrol. 2012, 414, 162-173.

9. Wang, Q.; Watanabe, M.; Hayashi, S.; Murakami, S. Using NOAA AVHRR data to assess flood damage in China. Environ. Monit. Assess. 2003, 82, 119-148.

10. Kuenzer, C.; Guo, H.; Huth, J.; Leinenkugel, P.; Li, X.; Dech, S. Flood mapping and flood dynamics of the Mekong Delta: ENVISAT-ASAR-WSM based time series analyses. Remote Sens. 2013, 5, 687-715.

11. Du, Z.; Linghu, B.; Ling, F.; Li, W.; Tian, W.; Wang, H.; Gui, Y.; Sun B.; Zhang, X. Estimating surface water area changes using time-series Landsat data in the Qingjiang River Basin, China. J. Appl. Remote Sens. 2012, 6, 063609.

12. Ling, F.; Cai, X.; Li, W.; Xiao, F.; Li, X.; Du, Y. Monitoring river discharge with remotely sensed imagery using river island area as an indicator. J. Appl. Remote Sens. 2012, 6, 063564.

13. Ma, M.; Wang, X.; Veroustraete, F.; Dong, L. Change in area of Ebinur Lake during the 1998-2005 period. Int. J. Remote Sens. 2007, 28, 5523-5533.

14. Muster, S.; Heim, B.; Abnizova, A.; Boike, J. Water body distributions across scales: a remote sensing based comparison of three arctic tundra wetlands. Remote Sens. 2013, 5, 1498-1523.

15. Ding, X.; Li, X. Monitoring of the water-area variations of Lake Dongting in China with ENVISAT ASAR images. Int. J. Appl. Earth Obs. Geoinf. 2011, 13, 894-901.

16. Giardino, C.; Bresciani, M.; Villa, P.; Martinelli, A. Application of remote sensing in water resource management: the case study of Lake Trasimeno, Italy. Water Resour. Manage. 2010, 24, 3885-3899.

17. Van Dijk, A.; Renzullo, L.J. Water resource monitoring systems and the role of satellite observations. Hydrol. Earth Syst. Sci. 2011, 15, 39-55.

18. Jain, S.K.; Saraf, A.K.; Goswami, A.; Ahmad, T. Flood inundation mapping using NOAA AVHRR data. Water Resour. Manage. 2006, 20, 949-959.

19. Huang, S.; Li, J.; Xu, M. Water surface variations monitoring and flood hazard analysis in Dongting Lake area using long-term Terra/MODIS data time series. Nat. Hazards. 2012, 62, 93-100. 
20. Lu, S.; Wu, B.; Yan, N.; Wang, H. Water body mapping method with HJ-1A/B satellite imagery. Int. J. Appl. Earth Obs. Geoinf. 2011, 13, 428-433.

21. Campos, J.C.; Sillero, N.; Brito, J.C. Normalized difference water indexes have dissimilar performances in detecting seasonal and permanent water in the Sahara-Sahel transition zone. J. Hydrol. 2012, 464, 438-446.

22. Petropoulos, G.P.; Kontoes, C.C.; Keramitsoglou, I. Land cover mapping with emphasis to burnt area delineation using co-orbital ALI and Landsat TM imagery. Int. J. Appl. Earth Obs. Geoinf. 2012, 18, 344-355.

23. Elmore, A.J.; Mustard, J.F. Precision and accuracy of EO-1 Advanced Land Imager (ALI) data for semiarid vegetation studies. IEEE Trans. Geosci. Remote Sens. 2003, 41, 1311-1320.

24. Helmer, E.H.; Ruzycki, T.S.; Wunderle, J.M.; Vogesser, S.; Ruefenacht, B.; Kwit, C.; Brandeis, T.J.; Ewert, D.N. Mapping tropical dry forest height, foliage height profiles and disturbance type and age with a time series of cloud-cleared Landsat and ALI image mosaics to characterize avian habitat. Remote Sens. Environ. 2010, 114, 2457-2473.

25. Goodenough, D.G.; Dyk, A.; Niemann, K.O.; Pearlman, J.S.; Chen, H.; Han, T.; Murdoch, M.; West, C. Processing Hyperion and ALI for forest classification. IEEE Trans. Geosci. Remote Sens. 2003, 41, 1321-1331.

26. Chen, S.; Fang, L.; Zhang, L.; Huang, W. Remote sensing of turbidity in seawater intrusion reaches of Pearl River Estuary-A case study in Modaomen water way, China. Estuar. Coast. Shelf Sci. 2009, 82, 119-127.

27. Chander, G.; Meyer, D.J.; Helder, D.L. Cross calibration of the Landsat-7 ETM+ and EO-1 ALI sensor. IEEE Trans. Geosci. Remote Sens. 2004, 42, 2821-2831.

28. Thenkabail, P.S.; Enclona, E.A.; Ashton, M.S.; Legg, C.; Dieu, M.J. D. Hyperion, IKONOS, ALI and ETM+ sensors in the study of African rainforests. Remote Sens. Environ. 2004, 90, $23-43$.

29. Soudani, K.; François, C.; Le Maire, G.; Le Dantec, V.; Dufrêne, E. Comparative analysis of IKONOS, SPOT, and ETM+ data for leaf area index estimation in temperate coniferous and deciduous forest stands. Remote Sens. Environ. 2006, 102, 161-175.

30. Amini, J. A method for generating floodplain maps using IKONOS images and DEMs. Int. J. Remote Sens. 2010, 31, 2441-2456.

31. Huang, C.; Davis, L.S.; Townshend, J.R.G. An assessment of support vector machines for land cover classification. Int. J. Remote Sens. 2002, 23, 725-749.

32. Mcfeeters, S.K. The use of the normalized difference water index (NDWI) in the delineation of open water features. Int. J. Remote Sens. 1996, 17, 1425-1432.

33. Rundquist, D.C.; Lawson, M.P.; Queen, L.P.; Cerveny, R.S. The relationship between the timing of summer-season rainfall events and lake-surface area. J. Am. Water Resour. Assoc. 1987, 23, 493-508.

34. $\mathrm{Xu}, \mathrm{H}$. Modification of normalized difference water index (NDWI) to enhance open water features in remotely sensed imagery. Int. J. Remote Sens. 2006, 27, 3025-3033.

35. Abou El-Magd, I.; Tanton, T.W. Improvements in land use mapping for irrigated agriculture from satellite sensor data using a multi-stage maximum likelihood classification. Int. J. Remote Sens. 2003, 24, 4197-4206. 
36. Qiao, C.; Luo, J.; Sheng, Y.; Shen, Z.; Zhu, Z.; Ming, D. An adaptive water extraction method from remote sensing image based on NDWI. J. Indian Soc. Remote Sens. 2012, 40, 421-433.

37. Ashish, D.; Mcclendon, R.W.; Hoogenboom, G. Land-use classification of multispectral aerial images using artificial neural networks. Int. J Remote Sens. 2009, 30, 1989-2004.

38. Ji, L.; Zhang, L.; Wylie, B. Analysis of dynamic thresholds for the normalized difference water index. Photogram. Eng. Remote Sens. 2009, 75, 1307-1317.

39. Jiang, Z.; Qi, J.; Su, S.; Zhang, Z.; Wu, J. Water body delineation using index composition and HIS transformation. Int. J. Remote Sens. 2012, 33, 3402-3421.

40. Ouma, Y.O.; Tateishi, R. A water index for rapid mapping of shoreline changes of five East African Rift Valley lakes: An empirical analysis using Landsat TM and ETM+ data. Int. J. Remote Sens. 2006, 27, 3153-3181.

41. Bai, J.; Chen, X.; Li, J.; Yang, L.; Fang, H. Changes in the area of inland lakes in arid regions of central Asia during the past 30 years. Environ. Monit. Assess. 2011, 178, 247-256.

42. Karsli, F.; Guneroglu, A.; Dihkan, M. Spatio-temporal shoreline changes along the southern Black Sea coastal zone. J. Appl. Remote Sens. 2011, 5, 053545.

43. Chander, G.; Markham, B.L.; Helde, D.L. Summary of current radiometric calibration coefficients for Landsat MSS, TM, ETM+, and EO-1 ALI sensors. Remote Sens. Environ. 2009, 113, 893-903.

44. Otsu, N. A threshold selection method from gray-level histograms. IEEE Trans. Syst. Man Cyber. 1979, 9, 62-69.

45. Foody, G.M. Status of land cover classification accuracy assessment. Remote Sens. Environ. 2002, 80, 185-201.

46. Sun, F.; Sun, W.; Chen, J.; Gong, P. Comparison and improvement of methods for identifying waterbodies in remotely sensed imagery. In. J. Remote Sens. 2012, 33, 6854-6875.

47. Keshava, N.; and Mustard, J.F. Spectral unmixing. IEEE Signal Process. Mag. 2002, 19, 44-57.

48. Pu, R.; Gong, P.; Yu, Q. Comparative analysis of EO-1 ALI and Hyperion, and Landsat ETM+ data for mapping forest crown closure and leaf area index. Sensors 2008, 8, 3744-3766.

49. Irons, J.R.; Masek, J.G. Requirements for a Landsat data continuity mission. Photogram. Eng. Remote Sens. 2006, 72, 1102-1108.

(C) 2013 by the authors; licensee MDPI, Basel, Switzerland. This article is an open access article distributed under the terms and conditions of the Creative Commons Attribution license (http://creativecommons.org/licenses/by/3.0/). 